University of Nebraska - Lincoln

DigitalCommons@University of Nebraska - Lincoln

1998

\title{
The Moderate Resolution Imaging Spectroradiometer (MODIS): Land Remote Sensing for Global Change Research
}

\author{
Christopher O. Justice \\ University of Virginia \\ Eric Vermote \\ University of Maryland \\ John R. G. Townshend \\ University of Maryland \\ Ruth Defries \\ University of Maryland \\ David P. Roy \\ University of Maryland, david.roy@sdstate.edu \\ See next page for additional authors
}

Follow this and additional works at: https://digitalcommons.unl.edu/nasapub

Part of the Physical Sciences and Mathematics Commons

Justice, Christopher O.; Vermote, Eric; Townshend, John R. G.; Defries, Ruth; Roy, David P.; Hall, Dorothy K.; Salomonson, Vincent V.; Privette, Jeffrey L.; Riggs, George; Strahler, Alan; Lucht, Wolfgang; Myneni, Ranga P.; Knyazikhin, Yuri; Running, Steve W.; Nemani, Rama R.; Wan, Zhengming; Huete, Alfredo R.; van Leeuwen, Wim; Wolfe, Robert E.; Giglio, Louis; Muller, Jan-Peter; Lewis, Philip; and Barnsley, Michael J., "The Moderate Resolution Imaging Spectroradiometer (MODIS): Land Remote Sensing for Global Change Research" (1998). NASA Publications. 28.

https://digitalcommons.unl.edu/nasapub/28

This Article is brought to you for free and open access by the National Aeronautics and Space Administration at DigitalCommons@University of Nebraska - Lincoln. It has been accepted for inclusion in NASA Publications by an authorized administrator of DigitalCommons@University of Nebraska - Lincoln. 


\section{Authors}

Christopher O. Justice, Eric Vermote, John R. G. Townshend, Ruth Defries, David P. Roy, Dorothy K. Hall, Vincent V. Salomonson, Jeffrey L. Privette, George Riggs, Alan Strahler, Wolfgang Lucht, Ranga P. Myneni, Yuri Knyazikhin, Steve W. Running, Rama R. Nemani, Zhengming Wan, Alfredo R. Huete, Wim van Leeuwen, Robert E. Wolfe, Louis Giglio, Jan-Peter Muller, Philip Lewis, and Michael J. Barnsley 


\title{
The Moderate Resolution Imaging Spectroradiometer (MODIS): Land Remote Sensing for Global Change Research
}

\author{
Christopher O. Justice, Eric Vermote, Member, IEEE, John R. G. Townshend, Ruth Defries, David P. Roy, \\ Dorothy K. Hall, Vincent V. Salomonson, Fellow, IEEE, Jeffrey L. Privette, Member, IEEE, George Riggs, \\ Alan Strahler, Member, IEEE, Wolfgang Lucht, Ranga B. Myneni, Yuri Knyazikhin, Steve W. Running, \\ Rama R. Nemani, Zhengming Wan, Member, IEEE, Alfredo R. Huete, Wim van Leeuwen, Robert E. Wolfe, \\ Louis Giglio, Jan-Peter Muller, Philip Lewis, and Michael J. Barnsley
}

\begin{abstract}
The first Moderate Resolution Imaging Spectroradiometer (MODIS) instrument is planned for launch by NASA in 1998. This instrument will provide a new and improved capability for terrestrial satellite remote sensing aimed at meeting the needs of global change research. The MODIS standard products will provide new and improved tools for moderate resolution land surface monitoring. These higher order data products have been designed to remove the burden of certain common types of data processing from the user community and meet the more general needs of global-to-regional monitoring, modeling, and assessment. The near-daily coverage of moderate resolution data from MODIS, coupled with the planned increase in high-resolution sampling from Landsat 7 , will provide a powerful combination of observations. The full potential of MODIS will be realized once a stable and well-calibrated time-series of multispectral data has been established. In this paper the proposed MODIS standard products for land applications are described along with the current plans for data quality assessment and product validation.
\end{abstract}

Index Terms - Earth Observing System-Moderate Resolution Imaging Spectroradiometer (EOS-MODIS), global change, monitoring, satellite remote sensing.

Manuscript received November 20, 1997; revised March 2, 1998.

C. O. Justice is with the University of Virginia, Charlottesville, VA 22903 USA and NASA's Goddard Space Flight Center, Code 923, Greenbelt, MD 20771 USA (e-mail: justice@kratmos.gsfc.nasa.gov).

E. Vermote, J. R. G. Townshend, R. Defries, and D. P. Roy are with the University of Maryland, College Park, MD 20742 USA.

D. K. Hall, V. V. Salomonson, and J. L. Privette are with NASA's Goddard Space Flight Center, Greenbelt, MD 20771 USA.

G. Riggs is with Research and Data Systems Corporation, Greenbelt, MD 20770 USA.

A. Strahler, W. Lucht, R. B. Myneni, and Y. Knyazikhin are with Boston University, Boston, MA 02215 USA.

S. W. Running and R. R. Nemani are with the University of Montana, Missoula, MN 59801 USA.

Z. Wan is with the University of California at Santa Barbara, Santa Barbara, CA 93106 USA.

A. R. Huete and W. van Leeuwen are with the University of Arizona, Tucson, AZ 85721 USA.

R. E. Wolfe is with Raytheon STX, NASA's Goddard Space Flight Center, Code 922, Greenbelt, MD 20771 USA

L. Giglio is with Science Systems and Applications, Inc., Lanham, MD 20706 USA.

J.-P. Muller and P. Lewis are with University College London, WC1E 6BT London, U.K.

M. J. Barnsley is with the University of Wales, SA2 8PP Swansea, U.K. Publisher Item Identifier S 0196-2892(98)04751-2.

\section{INTRODUCTION}

$\mathbf{T}$ HE MODERATE Resolution Imaging Spectroradiometer (MODIS) instrument has been designed to provide improved monitoring for land, ocean, and atmosphere research. The design of the land imaging component combines characteristics of the Advanced Very High Resolution Radiometer (AVHRR) and the Landsat Thematic Mapper, adding spectral bands in the middle and long-wave infrared (IR) and providing a spatial resolution of $250 \mathrm{~m}, 500 \mathrm{~m}$, and $1 \mathrm{~km}$. Spectral channels for improved atmospheric and cloud characterization have been included to permit both the removal of atmospheric effects on surface observations and the provision of atmospheric measurements. Summary tables describing the MODIS instrument, the spectral bands and their signal-to-noise and spatial characteristics are provided by Barnes et al. [1].

The first MODIS will be launched on the morning (AM1) platform of the Earth Observing System (EOS). MODIS will provide global, near-daily imaging capability, complementing the spectral, spatial, and temporal coverage of the other research instruments onboard the platform, i.e., Advanced Spaceborne Thermal Emission and Reflectance Radiometer (ASTER) [2], Multi-angle Imaging SpectroRadiometer (MISR) [3], and Cloud and Earth's Radiant Energy System (CERES) [4]. The use of coarse resolution imaging for global change research has developed over the last decade. MODIS land sensing will build on this heritage [5]-[11]. The EOSAM1 platform with MODIS and ASTER will fly in formation with Landsat 7 , providing a multiscale sampling system for land surface monitoring. The combination of coarse and high-resolution data is needed to realize the potential for a systematic global monitoring system for the land surface [12].

The MODIS Science Team is developing software to generate standard data products to meet the needs of global change research [13]. The standard products use peer-reviewed algorithms. The MODIS will provide improvements over existing global products and new products having high priority. The approach adopted by the land discipline group (MODLAND) is to provide a combination of basic surface variables of spectral reflectance, albedo, and land surface temperature (LST) as well as higher order variables, such as vegetation 
TABLE I

MODLAND Team and Their Product Responsibilities

\begin{tabular}{l|l}
\hline MODIS Team Member & MODIS Product \\
\hline E. Vermote & Surface Reflectance \\
\hline Z. Wan & Land Surface Temperature \\
\hline A. Strahler/J.-P. Muller & BRDF/Albedo \\
\hline A. R. Huete/C. O. Justice & Vegetation Indexes \\
\hline R. B. Myneni/S. W. Running & LAI/FPAR \\
\hline C. O. Justice/Y. J. Kaufman & Fires/Burned Area \\
\hline D. Hall & Snow/Ice/Sea Ice \\
\hline J. R. G. Townshend/A. Strahler & Land Cover/Land Cover Change \\
\hline S. W. Running & PSN/NPP \\
\hline
\end{tabular}

indexes (VI's), leaf area index (LAI), fraction of absorbed photosynthetically active radiation (FPAR), active fires, burned area, and snow and ice cover. The MODLAND team and their product responsibilities are shown in Table I.

At-launch bidirectional reflectance distribution function (BRDF)/Albedo and LAI/FPAR products will be enhanced during the first year of data provision to include data from the MISR instrument. MODIS will also generate a standard product of net primary productivity (NPP), using an ecosystem model, the MODIS LAI/FPAR product, and ancillary data. MODIS land cover and vegetation cover change products have been designed to meet the needs of the United States Global Change Research Program and the NASA programmatic focus on land cover and land use change (LCLUC) [14]. The suite of MODIS land products will meet several of the needs for satellite data outlined for the Global Climate Observing System [15] and is planned to complement the operational products generated by the emerging National Polar-Orbiting Operational Environmental Satellite System (NPOESS).

The algorithms for the MODIS products are described in the MODIS Algorithm Technical Background Documents, available on the World Wide Web (http://eospso.gsfc. nasa.gov/atbd/pg1.html).

\section{MODIS DATA}

There are five levels of MODIS land products in order of increasing level of processing. Level-1b data are generated from Level-0 by appending geolocation and calibration data to the raw instrument data.

\section{A. Vicarious Calibration of Land Level-1b Data}

Absolute calibration of Level-1b data is a critical step in developing a stable time-series. This emphasis on calibration for MODIS is a direct response to problems with the optical AVHRR channels that are not calibrated onboard. As a result, techniques known as vicarious calibration have been developed using radiances of known targets. The MODIS instrument will use multiple onboard calibration systems to ensure that a calibration accuracy of $2 \%$ relative to the sun's radiance [16]. Vicarious calibration techniques will continue to be of importance for MODIS, however, by providing independent validation of the onboard calibration system.

For MODIS, we are planning to apply a vicarious calibration technique that was developed and tested with AVHRR data
[17]. This technique uses high-altitude cloud and ocean observations to perform calibration in two steps: computing the calibration between bands and then the absolute calibration of the visible bands. A relative calibration between bands is established using high-altitude bright clouds, which can be considered as spectrally uniform in the visible and nearIR (NIR). Corrections for the effect of stratospheric ozone absorption and the atmosphere above the clouds are performed prior to derivation of the band ratio, which in this case, corresponds to the calibration ratio.

The procedure currently used for the AVHRR is to select high cloud of about $20-\mathrm{km}$ altitude using the $11-\mu \mathrm{m}$ band to identify cloudy pixels for which the apparent temperature is between 220 and $225 \mathrm{~K}$. Very cold clouds $(<220 \mathrm{~K})$ are avoided since they could be composed mostly of ice. The ratio between bands has been found to be very stable (less than $0.5 \% \mathrm{rms}$ ) and compares very well to the ratio derived using other stable sites, such as desert surfaces. The accuracy of this interband ratio was shown to be better than $1 \%$. As part of the procedure, clear areas of ocean are automatically selected and a combination of visible and NIR bands that depend mainly on Rayleigh scattering, and therefore, correct for aerosol effects, are used to compute an interband coefficient and compared to reference values to establish absolute calibration relative to the sun. In addition to calibration coefficients, the average aerosol optical thickness is computed. These data are used to filter cloudy and noisy areas, including those where aerosol optical thickness is too high. This method has shown good stability (2-3\% rms) and compares well with other vicarious calibration methods.

\section{B. MODIS Geolocation}

The MODIS instrument will provide data in 36 spectral bands at three different spatial resolutions. The detectors from the different bands are aligned to form spatial elements, each with 81 data channels (one from each of the 29,1-km resolution bands, four from each of the five 500-m resolution bands, and sixteen from each of the two 250-m resolution bands).

The MODIS earth location algorithm operates as part of the Level-1 (L1) processing system for MODIS data. MODIS data are unresampled throughout the Level-1 and Level-2 (L2) processing, and the earth location data fields are treated as additional attributes of the spatial elements that contain the MODIS data, thus describing the ground location explicitly for each spatial element.

The Level-1A earth location algorithm provides a single set of earth location fields for each spatial element. This spatial element is modeled as a detector in a band located near the optical axis of the instrument. This band is used to determine the locations of all of the bands.

The MODIS earth location algorithm produces eight pieces of information for each 1-km spatial element: geodetic latitude and longitude, height above the earth ellipsoid, satellite zenith angle, satellite azimuth, range to the satellite, solar zenith angle, and solar azimuth. The MODLAND team requires the earth location knowledge be accurate to 0.1 pixels at 
two standard deviations for the $1-\mathrm{km}$ bands to enable image registration for change detection.

MODIS will use ground control points (GCP's) for calibration of the instrument alignment. The goal of this calibration is to improve the inflight knowledge of the relationship between the MODIS instrument boresight and the platform navigation reference base. There is no current requirement on the accuracy of the knowledge of this error, however, there is a goal to measure this alignment to an accuracy of $3 \mathrm{arc} / \mathrm{s}$ at one standard deviation. Also, for interorbit variations, there is a goal for each 16-day period to measure the alignment to the same 3-arc/s accuracy throughout the orbit.

The production software will use the $250-\mathrm{m}$ bands and the GCP's to automatically measure residual errors. Two types of GCP data will be used for the land and oceans. Small image neighborhoods extracted from Landsat data will be used in a normalized grayscale correlation over land. In addition to image correlation, vector shoreline data will be used for GCP's. This involves a thresholding technique to separate land from water, typically using small islands, peninsulas, or lakes.

The control point residuals will also be used to monitor the stability of, and estimate refinements to, the instrument's geometric parameters. For example, the static errors in the EOS spacecraft attitude knowledge and the MODIS instrument pointing knowledge will be modeled as refinements to the preflight knowledge of the instrument-to-platform alignment.

In the first year after launch, analysis will be performed to estimate the systematic biases in the instrument alignment matrix by looking for constant biases in the distortions, estimate systematic biases correlated with scan angle and/or mirror side, and detect within-orbit thermal variations in the geometric parameters by correlating the distortions with the position in orbit relative to the sun.

\section{Land Product Levels}

L2 products are derived from calibrated radiances, previous MODIS products, and ancillary data and are computed and stored in the original sensor sampling space. Gridded products known as Level-2G (L2G) are generated from a single day of L2 data, reorganized, and stored in an earth-based grid, preserving all samples of the original L2 data [18].

Level 3 (L3) products are spatially resampled, averaged and/or temporarily composited to produce a single estimate of a geophysical variable for each grid location. The time scale of the L3 products varies from a single day to an entire year. L3 products at a reduced spatial resolution $\left(.5-1^{\circ}\right)$ will also be provided for the climate modeling community, as a series of climate modeling grids (CMG's). A full discussion of the MODIS grids and their projections is provided by Masuoka et al. [19]. The Level-4 (L4) products are generated by incorporation of MODIS data into models to estimate the geophysical variables.

The L2G method developed to store land products has several advantages over current methods for storing geophysical parameters at L2. Wide-angle sensors often make more than one observation of a given location with in a 24-h period. The new method stores an entire day of L2 data in
TABLE II

MODIS Summary PROCESSING LOADS AND STORAGE Volumes FOR THE LAND PRODUCTS

\begin{tabular}{l|l|l}
\cline { 2 - 3 } & Processing (MFLOPS) & Archiving (GB/day) \\
\hline Level-2 and L2G & 990 (GSFC) & 177 (EDC) 5(NSIDC) \\
\hline Level-3 at EDC & 1764 & 40 \\
\hline Level-3 at NSIDC & 70 & 8 \\
\hline
\end{tabular}

a grid format. Multiple layers are used to store samples from different orbits acquired on the same day, so that all instrument observations for a given location are preserved. MODLAND L3 algorithms can take advantage of this format to exploit multiple samples of the surface more fully than conventional compositing approaches.

Initially, two products will be archived and distributed in the L2G format: land surface reflectance and thermal anomalies. Two supplemental data sets of the viewing geometry and observation pointers will also be available in the L2G format. The observation pointer data stores information about the spatial relationship between each sensor observation and output grid cell.

In the current design, the production of the MODIS land products is split among three EOS Distributed Active Archive Centers (DAAC's) at the Goddard Space Flight Center (GSFC), Greenbelt, MD, the EROS Data Center (EDC), Sioux Falls, SD, and the National Snow and Ice Data Center (NSIDC), Boulder, CO. The L2 and L2G products will be produced at GSFC. The L3 snow and sea ice products will be produced at NSIDC, and the remainder of the L3 and L4 land products will be produced at EDC. Due to the high spatial resolution of the land bands, the land products use about $50 \%$ of the processing resources budgeted for MODIS. Of the computational resource budget allocated for the land products, less than $10 \%$ is needed by the L2 processes, $30 \%$ by the L2G processes, and $60 \%$ by L3 and L4 processes.

When in full operation, an average of more than $200 \mathrm{~GB}$ of MODIS land products will be produced and archived each day. A single 16-bit geophysical variable stored at $250 \mathrm{~m}$ covering the land area of the earth is $5 \mathrm{~GB}$. Table II shows a summary of the product processing loads and archive volumes planned for MODIS. The distributed production of land products requires reliable and efficient inter-DAAC communication networks. For operational daily production, about $400 \mathrm{~GB}$ of data will be transferred daily between the DAAC's, primarily from GSFC to EDC.

\section{LAND PRODUCTS}

\section{A. Surface Reflectance}

The MODIS atmospheric correction algorithm over land will be applied to bands $1-7$, centered at $648,858,470,555$, 1240, 1640, and $2130 \mathrm{~nm}$.

The MODIS atmospheric correction algorithm uses aerosol and water vapor information derived from the MODIS data, corrects for adjacency effects, and takes into account the directional properties of the observed surface. Previous operational correction schemes have assumed a standard atmosphere with 
zero or constant aerosol loading and a uniform, Lambertian surface. The MODIS algorithm relies on the modeling of atmospheric effects, as described in the Second Simulation of the Satellite Signal in the Solar Spectrum radiative code $(6 \mathrm{~S})$ [20], and is simplified in the MODIS code for operational application. The code is fully documented and includes simulation of the effects of the atmospheric point spread function and surface reflectance directionality. Currently the $6 \mathrm{~S}$ code is being used as a reference to test the correct implementation of the MODIS atmospheric correction algorithm.

The surface reflectance product is an estimate of the surface spectral reflectance for each band, as it would have been measured at ground level, if there were no atmospheric scattering or absorption. The correction procedure stems from the modeling work by Tanré et al. [21]. The correction scheme includes corrections for the effects of atmospheric gases, aerosols, and thin cirrus clouds and is applied to all noncloudy L1B pixels that pass the L1B quality control tests. The surface reflectance product is the input for the generation of several land products: VI's, BRDF/albedo, thermal anomaly, and FPAR/LAI.

Atmospheric correction for heterogeneous ground conditions has been addressed by several researchers [21]-[23]. The correction approach adopted by MODIS is to assume that the signal received by the satellite is a combination of the reflectance of the target pixel and reflectances from surrounding pixels, each weighted by their distance from the target. Because the apparent signal at the top-of-theatmosphere (TOA) comes from the target and adjacent pixels, this effect is called the adjacency effect. The correction involves inverting the linear combination of reflectances to solve for the reflectance of the target pixel. It should be noted that this effect will be less important for MODIS with 250-500-m pixels than it is for higher spatial resolution data, e.g., the Landsat Thematic Mapper (TM).

The result of correction using a classical Lambertian approach is inexact due to a coupling between the surface BRDF and atmosphere BRDF [24]. The difference between the true ground reflectance and the reflectance computed without coupling can reach 0.02 for off-nadir views.

The contribution of the target to the signal at TOA is decomposed as the sum of the following four terms:

1) photons directly transmitted from the sun to the target and directly reflected back to the sensor;

2) photons scattered by the atmosphere then reflected by the target and transmitted directly to the sensor;

3) photons transmitted directly to the target but scattered by the atmosphere on their way to the sensor;

4) photons having at least two interactions with the atmosphere and one with the target.
The equation is written as [25]

$$
\begin{aligned}
& \rho_{\mathrm{TOA}}\left(\mu_{s}, \mu_{v}, \phi_{s}-\phi_{v}\right) \\
& =\rho_{R+A}+e^{-\tau / \mu_{v}} e^{-\tau / \mu_{s}} \overbrace{\rho_{s}\left(\mu_{s}, \mu_{v}, \phi_{s}-\phi_{v}\right)}^{(a)} \\
& +\overbrace{e^{-\tau / \mu_{v}} t_{d}\left(\mu_{s}\right) \bar{\rho}}^{(b)}+\overbrace{e^{-\tau / \mu_{s}} t_{d}\left(\mu_{v}\right) \overline{\rho^{\prime}}}^{(c)} \\
& \text { (d) } \\
& +\overbrace{t_{d}\left(\mu_{s}\right) t_{d}\left(\mu_{v}\right) \overline{\bar{\rho}}+\frac{T_{R+A}\left(\mu_{s}\right) T_{R+A}\left(\mu_{v}\right) S(\overline{\bar{\rho}})^{2}}{1-S \overline{\bar{\rho}}}}
\end{aligned}
$$

where $\rho_{\mathrm{TOA}}$ is the top of the atmosphere reflectance, $\rho_{R+A}$ is the atmospheric intrinsic reflectance, $\tau$ is the atmosphere optical thickness (Rayleigh + aerosol), $\mu_{s}$ is the cosine of the solar zenith angle, $\mu_{v}$ is the cosine of the view zenith angle, $\rho_{s}$ is the surface bidirectional reflectance function, $\phi_{s}-\phi_{v}$ is the difference between solar and view azimuth, $t_{d}\left(\mu_{s}\right)$ is the diffuse downward atmospheric transmission, $t_{d}\left(\mu_{v}\right)$ is the diffuse upward atmospheric transmission, $T_{R+A}\left(\mu_{s}\right)$ is the total (diffuse + direct) downward atmospheric transmission, $T_{R+A}\left(\mu_{s}\right)$ is the total (diffuse + direct) upward atmospheric transmission, and the other terms in $\rho$ are convolution of the atmospheric downward or upward radiation field with the surface bidirectional reflectance function.

In our approach, we use the ratio between the estimated BRDF coupled with the atmosphere and the actual surface BRDF to correct the measured values, as shown in (2) at the bottom of the page.

As currently developed, the atmospheric correction process uses the MODIS calibrated radiances and estimates the surface reflectance. In addition to the estimates of the surface reflectance, the data product contains the following quality assurance (QA) information for each pixel:

1) integrity of the surface reflectance estimate;

2) successful completion of the correction scheme;

3) presence of cloud (clear, cloudy, mixed, shadow);

4) presence of cirrus cloud (no cirrus, low, average, high);

5) source of aerosol information: MODIS aerosol, climatology;

6) presence of aerosol (low, average, high);

7) source of water vapor information: MODIS water vapor, climatology;

8) source of ozone information: MODIS ozone, climatology;

9) whether the pixel is land or water.

The current prelaunch version of the software reads MODIS synthetic data [26] and writes MODIS products using the hierarchical data format (HDF) structure. Using this code, we were able to successfully implement the correction for the

$$
\begin{aligned}
\rho_{\mathrm{TOA}}\left(\mu_{s}, \mu_{v}, \phi\right)= & \rho_{R+A}+e^{-\tau / \mu_{v}} e^{-\tau / \mu_{s}} \rho_{s}\left(\mu_{s}, \mu_{v}, \phi\right) \\
& +\rho_{s}\left(\mu_{s}, \mu_{v}, \phi\right)\left[\begin{array}{c}
e^{-\tau . \mu_{v}} t_{d}\left(\mu_{s}\right) \overline{\rho^{*}}+e^{-\tau / \mu_{s}} t_{d}\left(\mu_{v}\right) \overline{\rho^{*}}+t_{d}\left(\mu_{s}\right) t_{d}\left(\mu_{v}\right) \overline{\overline{\rho^{*}}}+ \\
\rho_{s}\left(\mu_{s}, \mu_{v}, \phi\right) \frac{T_{R+A}^{\downarrow}\left(\mu_{s}\right) T_{R+A}^{\uparrow}\left(\mu_{v}\right) S\left(\overline{\bar{\rho}^{*}}\right)^{2}}{1-S \overline{\bar{\rho}}}
\end{array}\right]
\end{aligned}
$$




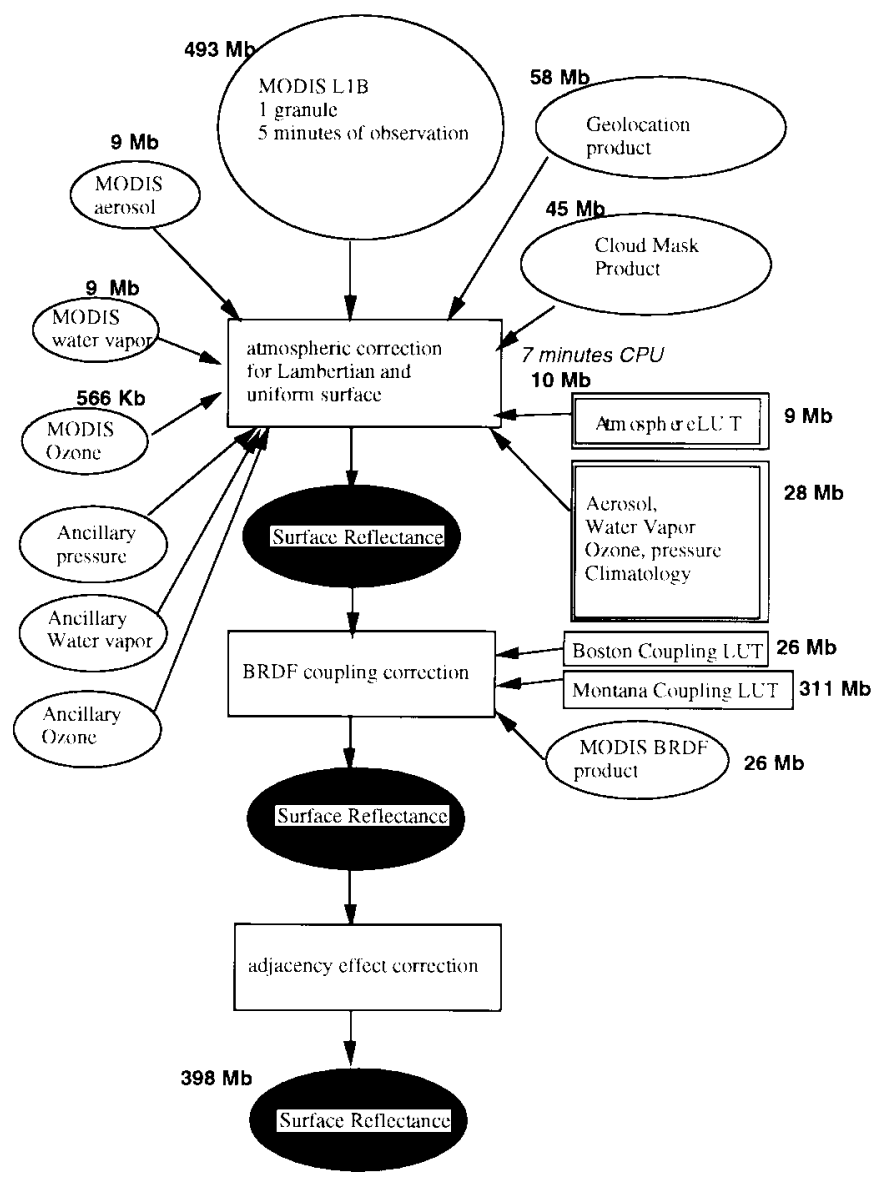

Fig. 1. Overview of the current software and data volume requirements for the MODIS surface reflectance algorithm.

atmospheric point spread function and the coupled atmosphere surface BRDF. Each of these corrections can be selectively activated. Fig. 1 gives an overview of the current software, data volumes, and central processing unit (CPU) requirements.

We are currently working on operational prototypes using existing data sources and the prelaunch algorithm. In addition to AVHRR and Landsat TM, we are using test data sets from the Polarization and Directionality Of the Earth's Reflectances (POLDER) instrument and the Sea-viewing Wide Field-ofview Sensor (SeaWiFS) instruments for a selected number of validation sites.

\section{B. Land Surface Temperature}

Land surface temperature (LST) is one of the key variables needed to describe land surface processes. It is required for a wide variety of climatic, hydrological, ecological, and biogeochemical studies. For example, the MODIS LST product will be used as input for models of the LST diurnal cycle, cloud and atmospheric vertical profiles, surface-emitted energy fluxes, and hydrological processes. The MODIS LST product will provide global day and night land surface temperature and emissivity at 1 - and 5-km spatial resolutions and a derivative CMG product at an equal-angle projection at grids of half degree latitude and longitude, with a daily, eight-day, and monthly temporal frequency.
The accuracy specification for the MODIS LST product is $1 \mathrm{~K}$ for temperatures in the $270-320-\mathrm{K}$ range, which requires better than a $0.01-\mathrm{K}$ accuracy for the band-averaged emissivities in the $10-12.5-\mu \mathrm{m}$ region. Two algorithms have been developed for retrieving LST from MODIS data. A generalized split-window LST algorithm will be used for surfaces with relatively stable emissivities that can be determined from land cover types and a database of surface emissivities [27], [28].

A new day/night LST algorithm [29] will be used to simultaneously retrieve surface band-averaged emissivities and day and night temperatures from day-night pairs of MODIS thermal infrared (TIR) data in bands centered at 3.75, 3.95, $4.05,8.55,11.03,12.02$, and $13.33 \mu \mathrm{m}$. The advantage of using daytime data from the MODIS middle IR bands is that the day/night LST model can be used to determine the middle IR, surface reflectance component. Combining the night data in these three bands and day/night data in the other four MODIS bands makes it possible to simultaneously retrieve surface emissivity and temperature. The advantage of including four atmospheric variables (near-surface air temperature and column water vapor in daytime and nighttime) is that atmospheric variations are considered in the retrieval procedure so that uncertainties in the initial atmospheric conditions could be reduced and a better self-consistent solution of the surface emissivity and temperature could be reached.

Lookup tables (LUT's) and a linear interpolation scheme are used to achieve computational efficiency for operational production. The LUT's for atmospheric transmission, path radiance, downward thermal irradiance, and solar direct-beam diffuse irradiance are calculated using the MODTRAN3 code. The set of 14 nonlinear equations in the LST algorithm is solved with the statistical regression and the least-squares-fit method. The day/night LST processing code has been tested with synthetic MODIS data.

Comprehensive sensitivity and error analysis has been made to evaluate the performance of the day/night LST algorithm and its dependence on surface optical properties, the ranges of atmospheric conditions and surface temperatures, and the noise-equivalent temperature difference ( $N E \delta T$ and calibration accuracy specifications of the MODIS instrument. In cases with a systematic calibration error of $0.5 \%$, the standard deviations of errors in retrieved surface day and night temperatures fall between $0.4-0.5 \mathrm{~K}$ over a wide range of surface temperatures for midlatitude summer conditions. The standard deviations of errors in retrieved emissivities at 11.03, 12.02 $\mu \mathrm{m}$, are 0.009 , and the maximum error in retrieved surface temperature falls between 2 and $3 \mathrm{~K}$.

The day/night LST algorithm has been tested with TIR spectral BRDF measurement data, MODIS Airborne Simulator (MAS) data, and field measurement data [30], [31]. We have developed a multimethod strategy for validating the LST algorithms and applied this strategy in field campaigns over the past three years in Nevada, California, and Canada. Table III shows a comparison of LST values retrieved from MAS data and measured by IR spectrometer (MIDAC), IR thermometer (Heimann), and seven thermistors near the center of the Railroad Valley, NV, playa in June 1997. The numbers in parentheses are the standard deviations of the thermistor data. 
TABLE III

LST Values Measured at the Railroad Valley, NV, Playa at 11:12 PDT ON JUNE 23, 1997, AND 19:59 PDT ON JUNE 24, 1997

\begin{tabular}{l|l|l|l}
\hline Sensor & Daytime LST $\left({ }^{\circ} \mathbf{C}\right)$ & Evening LST $\left({ }^{\circ} \mathbf{C}\right)$ & Comments \\
\hline MAS & 46.5 & 22.5 & $2 \times 2$ pixels \\
\hline MIDAC & 46.0 & 22.8 & $\begin{array}{l}\text { view angle } \\
0^{\circ}\end{array}$ \\
\hline Heimann & 47.1 & 22.3 & $\begin{array}{l}\text { emiss. corr. } \\
2.1{ }^{\circ} \mathrm{C}\end{array}$ \\
\hline Thermistors & 46.5 & $23.1(0.5)$ & mean (s.d.) \\
\hline
\end{tabular}

Note that the emissivity was set to 1.0 in the IR thermometer to get the equivalent brightness temperature in the 8.14$\mu \mathrm{m}$ broadband of the thermometer sensitivity, and then LST values were calculated from the brightness temperature values, measured surface emissivity value, and estimated downward thermal irradiance in this broadband. This procedure corrects the effects of surface emissivity and atmosphere on LST (a difference of $21{ }^{\circ} \mathrm{C}$ between the brightness temperature and the calculated LST), giving the LST values from Heimann in Table III.

The retrieved LST and band emissivity images are shown in Fig. 2. The topographic effect on the LST is clearly shown in both daytime and evening LST images, but not in the emissivity images. As expected, the LST is higher on the eastfacing slopes in the mountain ranges in morning and higher on the west-facing slopes in evening. We can see that the pixels of small ponds, wetlands, and vegetated lands have lower LST values and higher emissivity values compared to their neighboring pixels.

A similar strategy will be used for postlaunch validation, including comparison of LST's obtained from ASTER and AVHRR data over a range of land cover types in different seasons. Validation sites are being selected in relatively uniform and flat areas to facilitate validation at multiple viewing angles.

The postlaunch development of the LST algorithm will include the extension to both EOS-AM1 and EOS-PM1 MODIS data and the combination of MODIS BRDF and Geostationary Operational Environmental Satellite (GOES) data to study LST angular dependence and explore the synergy.

\section{Albedo and Land Surface BRDF Products}

Land surface reflectance is highly anisotropic. Its value as observed from space depends both on the angle at which the surface is viewed and on the angle of solar illumination. This is mainly due to directional effects in the radiative transfer within vegetation canopies or soils, geometric effects, such as shadow-casting and mutual shadowing due to the threedimensional (3-D) structure of vegetation and other surface elements, and to the anisotropy of the optical properties of scene constituents (for example, soil particles and leaves). This anisotropy is characterized by the BRDF of the land surface [32]. In remote-sensing data processing, knowledge of the BRDF allows us to normalize observations with varying viewing and illumination angles (for MODIS, across the swath and with latitude and season) to a standard geometry [33], [34]. With respect to land surface and vegetation modeling,

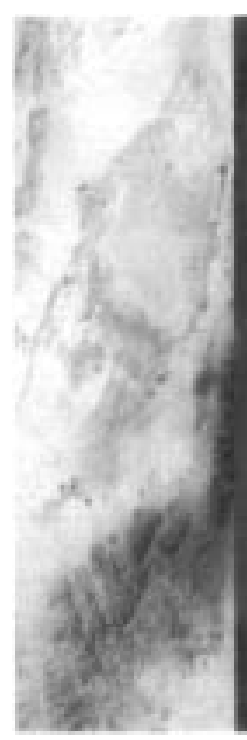

(a)

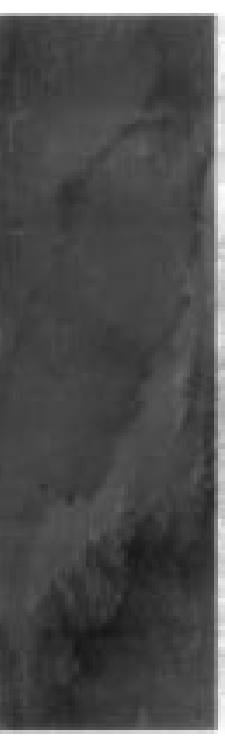

(b)

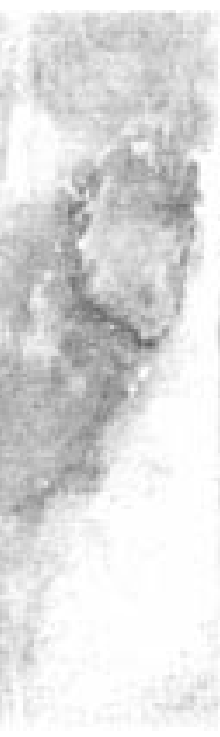

(c)

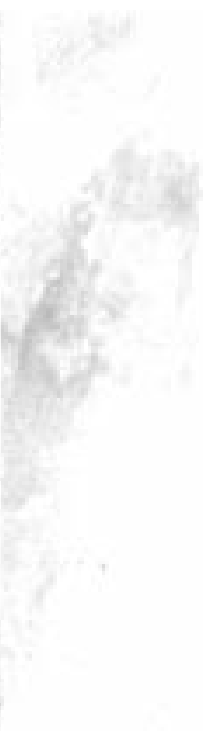

(d)
Fig. 2. LST and emissivity images retrieved from MAS data acquired in the field campaign at Railroad Valley, NV, on June 23-24, 1997. (a) LST at 11:11 PDT, June 23. (b) LST at 19:59 PDT, June 24. (c) Emissivity in MAS band 30 (centered at $3.75 \mu \mathrm{m}$ ). (d) Emissivity in MAS band 42 (centered at $8.55 \mu \mathrm{m}$ ). There are 256 gray levels in both LST and emissivity images. The temperature range is from -5 to $58.75^{\circ} \mathrm{C}$ in steps of $0.25^{\circ} \mathrm{C}$. The emissivity range is from 0.49 to 1.0 in steps of 0.002 .

the parameters that describe the BRDF relate to LAI [35] and surface or vegetation structure [36].

Land surface albedo is a related but more general property of importance to modeling the earth's meteorological, climatological, and biospheric systems [37], [38]. Defined as the fraction of downwelling solar shortwave radiation that is reflected back into the atmosphere by the surface, it characterizes the radiometric interface between the land and the atmosphere. It provides the lower boundary condition to any radiative transfer scheme in the atmosphere [39] and hence influences the TOA radiation budget, cloud formation, precipitation, and general circulation [40]. With respect to the land surface, it quantifies the shortwave energy input into the biosphere, influencing the surface energy budget through the latent heat flux and evapotranspiration. Over vegetated surfaces, albedo is strongly influenced by the optical and structural properties of vegetation and may hence serve to monitor them.

The MODIS BRDF/albedo product will provide both the BRDF and the albedo of the global land surface for use in climate change research and ecological modeling [41]. BRDF and albedo will be calculated from a 16-day time series of atmospherically corrected multiangular reflectance observations with a spatial resolution of $1 \mathrm{~km}$. In four spectral bands, three visible and one NIR, data from MODIS and the MISR instrument will be combined to derive the product with improved angular coverage. In three MODIS land bands beyond the NIR, the product will be derived from MODIS data alone, as there are no corresponding MISR bands. Albedo will also be given for all visible, NIR, and shortwave bands.

The observed MODIS and MISR multiangular reflectances are used to invert a semiempirical BRDF model, the Ambrals BRDF model [41] [42], for its three parameters. This model, 
of the so-called kernel-driven type [43], describes surface reflectance as a linear combination of three scattering terms: 1) isotropic scattering, 2) radiative transfer-type volume scattering (as from homogeneously layered vegetation canopies, such as grass or croplands), and 3) geometric-optical surface scattering (as from discrete vegetation canopies or other rough surfaces, such as sparse forests or rough, barren fields or deserts), terms that are derived from physical BRDF models [44]. The Ambrals BRDF model has been validated using fieldobserved data sets and successfully applied to airborne and satellite-observed multiangular data sets [42], [45], [46].

The MODIS BRDF/albedo algorithm was tested using the National Oceanographic and Atmospheric Administration (NOAA)-14 AVHRR and GOES-8 Imager data over New England [47]. Data from these instruments were calibrated, geolocated, and carefully cloud-cleared at a spatial resolution of $1 \mathrm{~km}$ for a time period in September 1995. Each of 160800 pixels was inverted using the Ambrals BRDF model. Fig. 3(a) shows in the left panel the bidirectional reflectance normalized to nadir viewing and a sun position overhead in the red band. The right panel of Fig. 3(b) shows the corresponding bihemispherical (white-sky) land surface albedo. Due to volume scattering and shadow-casting effects at off-nadir angles, the contrast is diminished when compared to the reflectance image, illustrating the influence of surface reflectance anisotropy on albedo and the importance of correcting for it. Similar testing has also been performed for a Sahelian environment [45], [12] and is in progress for a tropical environment in Amazonia. Studies are underway to address the temporal and spatial consistency of the inversions, seasonal and interannual changes, and some aspects of the relationship between BRDF/albedo and land cover type.

The MODIS BRDF/albedo product will provide global data sets of BRDF model parameters, geometrically adjusted reflectances, and albedo similar to those shown in Fig. 3. It will supply improved definitions of the radiometric condition of the land surface for a range of subsequent inferences in modeling of the earth's atmosphere and biosphere.

\section{MODIS VI's}

VI's have emerged as an important tool for a number of earth science and resource management applications [4], [9], [10], [48], [49]. The MODIS VI products have been designed for precise, seasonal and interannual monitoring of the earth's vegetation. Two indexes are planned as MODIS products. The normalized difference vegetation index (NDVI) will maintain continuity with the AVHRR-NDVI data record, which has provided a time series of seasonal and interannual variations since 1982 and an enhanced vegetation index (EVI), which will extend sensitivity into dense forested biomes and agricultural areas while reducing canopy background and aerosol sources of noise.

The NDVI was originally developed to enhance the vegetation signals over sparsely vegetated rangelands [50]

$$
\mathrm{NDVI}=\left(\rho_{\text {nir }}-\rho_{\text {red }}\right) /\left(\rho_{\text {nir }}+\rho_{\text {red }}\right)
$$

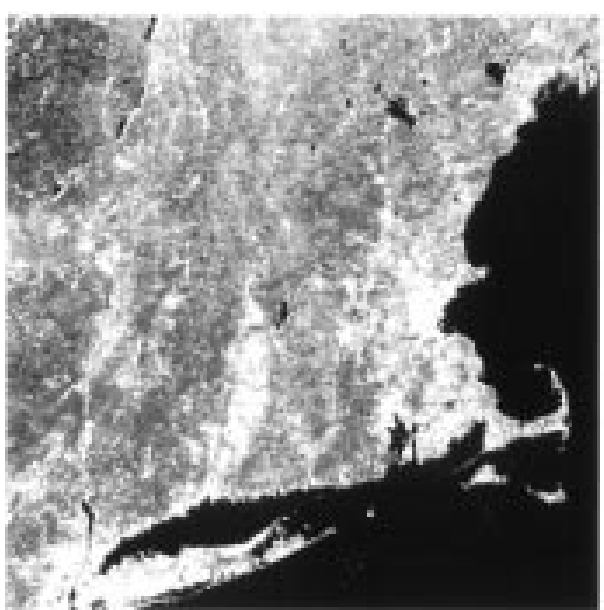

(a)

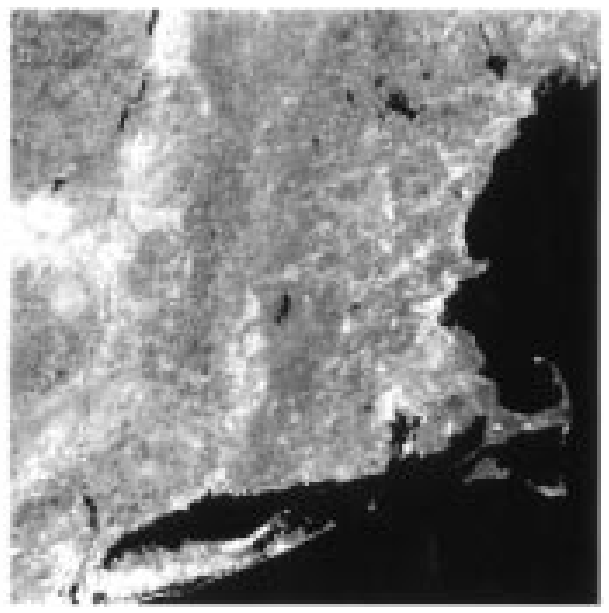

(b)

Fig. 3. Ambrals BRDF model inversions of combined AVHRR and GOES observations of New England from September 1995. Red band, spatial resolution $1 \mathrm{~km}$. (a) BRDF-derived reflectance for nadir viewing and sun overhead. Landscape patterns are clearly visible: the bright cities of Boston, MA, Providence, RI, and New York, NY (center right, lower right, and lower left); forested regions in the Adirondacks, Catskills, and Berkshires (upper left, lower left, and north-south in left center); and the Connecticut, Hudson, and Mohawk river valleys with their altered vegetation and agriculture (lower center, north-south on the left, and east-west on the upper left). (b) Bihemispherical (white-sky) albedo. Both images are scaled the same using a linear grayscale from 0.0 to 0.08 .

The NDVI retains certain favorable ratioing properties that reduce noise and uncertainty associated with instrument characteristics and external sources of noise (e.g., cloud shadows), but there are certain disadvantages, including nonlinearity and scaling problems, an asymptotic (saturated) signal at high leaf biomass, and sensitivity to exposed soil backgrounds with sparse vegetation [51].

The EVI has been developed to optimize the vegetation signal while minimizing aerosol and canopy background sources of uncertainty [52]. The equation takes the form

$$
\mathrm{EVI}=2.5\left(\rho_{\text {nir }}-\rho_{\text {red }}\right) /\left(L+\rho_{\text {nir }}+C_{1} \rho_{\text {red }}-C_{2} \rho_{\text {blue }}\right)
$$

where $L$ is the canopy background correction and snow correction that addresses differential NIR and red radiant transfer (transmittance) through a canopy and $C 1$ and $C 2$ 


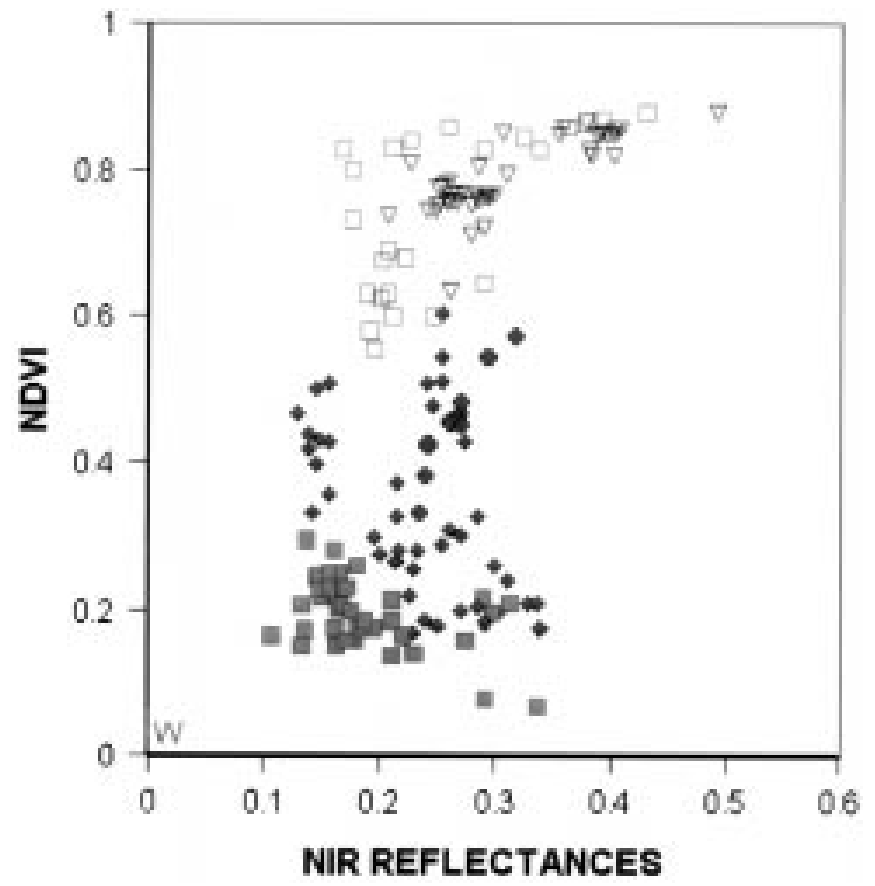

(a)

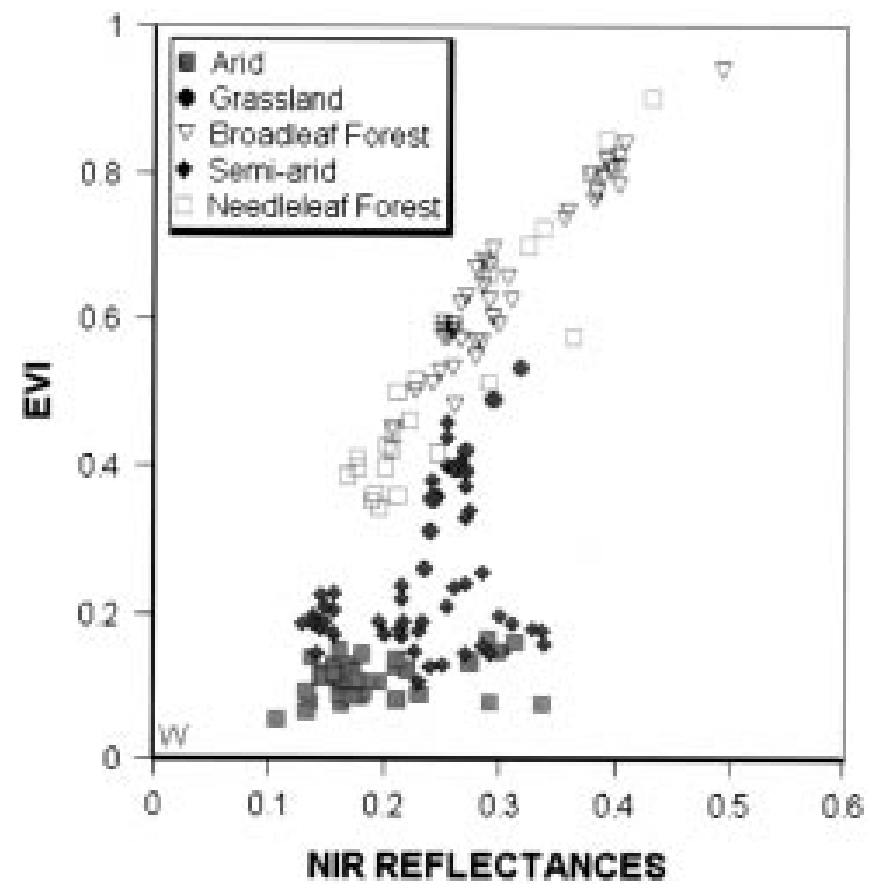

(b)

Fig. 4. The response of two VI's, (a) NDVI and (b) EVI, over a global range of vegetated canopies derived from MODIS simulated, and atmospherically corrected, Landsat TM images (W denotes Water).

are the coefficients of the aerosol term, which uses the blue band to correct for aerosol effects in the red band [53]. This equation doesn't ratio bands to remove noise, and thus, it is susceptible to the level of noise remaining in the MODIS surface reflectance product. The coefficients currently used, $L=1 ; C 1=6$; and $C 2=7.5$, are fairly robust and have been applied to Landsat TM, ground observation data, and simulated canopy model data.
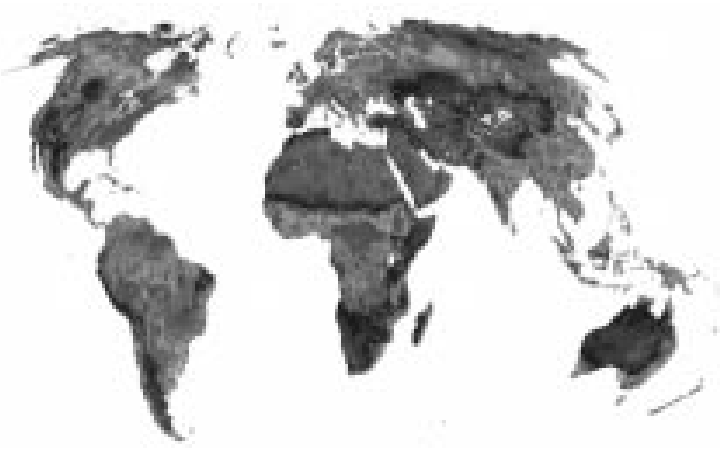

(a)

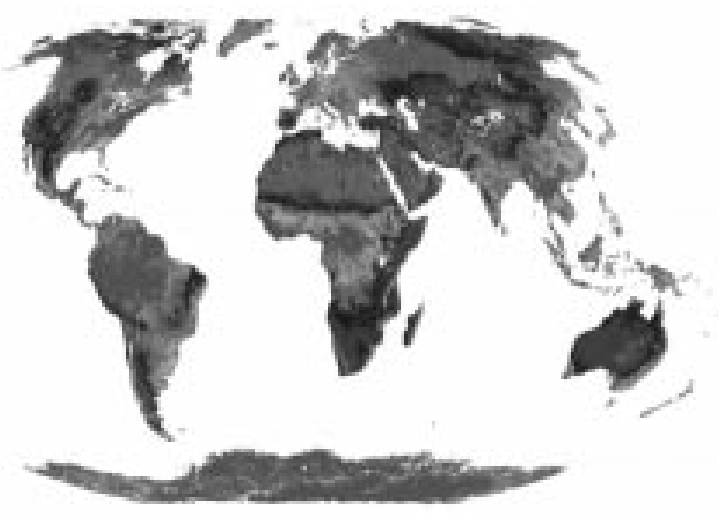

(b)

Fig. 5. Example of (a) NDVI and (b) enhanced EVI generated from SeaWiFS data. Composite from September 16 to October 2, 1997.

Fig. 4 shows the resulting response of these VI's over a range of vegetation types derived from MODIS simulated data and atmospherically corrected Landsat TM images. The NDVI, with its asymptotic behavior at high-leaf biomass conditions, has been shown to be useful in the derivation of FPAR and fractional cover, which have similar asymptotic patterns. The EVI, with its extended sensitivity, is more responsive to canopy structural parameters, such as LAI. Some postlaunch refinements are expected with the coefficients of the EVI, based upon the true response of the MODIS. Fig. 5(b) shows an early example of the EVI product generated from global SeaWiFS data. In comparison with the NDVI [Fig. 5(a)], the EVI product shows increased variability in rain forest regions and reduced effects of smoke but also has a high EVI value for snow-covered surfaces.

The MODIS instrument will acquire one-two-day, bidirectional reflectance data of the earth's surface under a wide range of solar illumination and sensor viewing angles $\left( \pm 55^{\circ}\right)$. Due to frequent cloud cover and variable sun-target-sensor geometry, MODIS data will be composited in time and space for accurate and continuous monitoring of terrestrial land cover conditions. The MODIS VI products are based on temporal compositing of daily, cloud-screened, and atmospherically corrected, surface bidirectional reflectances prior to the computation of the VI. With atmospherically corrected data, the maximum value compositing (MVC) technique developed by Holben [54] and applied by James and Kalluri [55] becomes less useful and surface anisotropic properties become relatively 


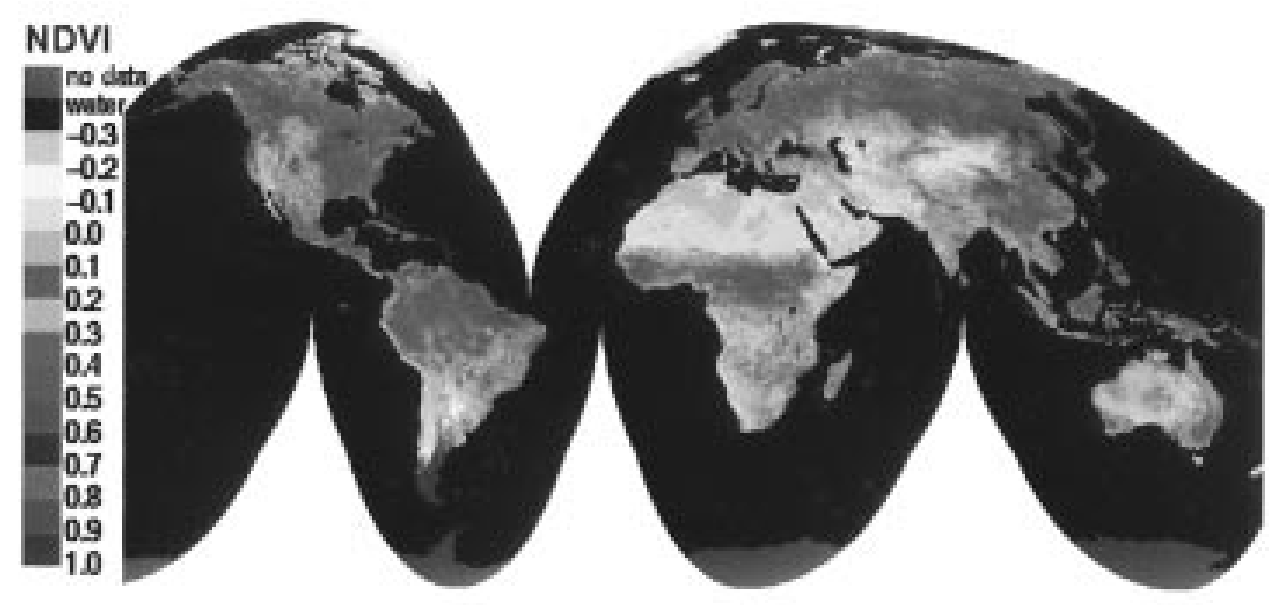

Fig. 6. Global NDVI image, based on the MODIS compositing algorithm (AVHRR data, August 1-16, 1988, 8-km spatial resolution).

more pronounced [56]. The approach adopted for MODIS compositing is based on standardization of the anisotropic reflectances to a constant view angle at a representative solar zenith angle. Nadir reflectances are the preferred choice for the following reasons [57]:

- nadir pixels have the finest spatial resolution with minimal distortions;

- atmospheric correction is most reliable and accurate for near-nadir measurements;

- established biophysical relationships between VI's and ground measurements are based on nadir measurements.

An empirical model developed by Walthall et al., [58] is utilized to derive nadir-equivalent reflectance data for each pixel at 16-day intervals

$$
\rho_{\lambda}\left(\Theta_{v}, \Phi_{s}, \Phi_{v}\right)=a_{\lambda} \Theta_{v}^{2}+b_{\lambda} \Theta_{v} \cos \left(\Phi_{v}-\Phi_{s}\right)+C_{\lambda}
$$

where the reflectances $\rho \lambda$, are modeled as a function of view zenith angle $\left(\Theta_{v}\right)$ and sun $\left(\Phi_{s}\right)$ and view azimuth angles $\left(\Phi_{v}\right)$. The model parameters $a_{\lambda}$ and $c_{\lambda}$ are obtained using a leastsquares curve fitting procedure, with $c_{\lambda}$ equal to the reflectance at nadir.

After inversion of the model, nadir-equivalent reflectances and VI values are computed using forward modeling. A minimum of five clear acquisitions from the same pixel are needed for the inversion. If the nadir reflectance retrieval from the BRDF model is not possible due to cloud cover, a maximum VI compositing is applied within a limited range of view angle. A global NDVI image, derived using the MODIS compositing algorithm, is shown in Fig. 6. The nadir-view composite resulted in a greater proportion of near-nadir pixel values such that average continental-scale NDVI values were up to $30 \%$ lower than the off-nadir values selected with the MVC approach [57]. For MODIS VI products, quality control flags, sun and view angles, geolocation, and the reflectances used in computation of the VI's will also be generated. The atmospherically corrected reflectances allow the user the means for computation of additional, experimental, or biomespecific VI's.
The following global VI maps depicting spatial and temporal variations in vegetation activity will be derived using MODIS data from atmospherically corrected and nadiradjusted surface reflectances:

- 250-m high resolution NDVI (16-day and monthly);

- 1-km standard resolution NDVI and EVI (16-day and monthly);

- 25-km coarse resolution NDVI and EVI (16-day and monthly - CMG product).

Postlaunch refinements to the compositing procedure include the use of previous BRDF results in the current compositing period to raise the proportion of nadir-equivalent data selected. MODIS will provide data products with improved sensor characteristics (e.g., calibration), better cloud detection and screening capability, atmospheric correction, and nadiradjusted surface reflectance values. Only sun angle effects, residual aerosols, and instrument uncertainties associated with band-to-band registration and scene registration will limit the utility of the MODIS VI data record.

In order to provide precise measures of vegetation spatial and temporal variations, the VI's require careful absolute and relative radiometric calibration. Field validation exercises examining L1B radiometric calibration activities, the atmospheric correction and the surface reflectance product will provide important insight into the VI product performance. Relative calibration, filter degradation, and orbital drift will be monitored over a series of calibration test sites, including desert areas and dense tropical forests.

Validation of the biophysical component of the VI products will be undertaken to ensure that the spatial and temporal variations depicted by the VI are associated with real surface vegetation changes. Our activities in biophysical validation are closely coupled with the LAI/FPAR and land cover products and will include field sampling and radiometric measurement at a number of test sites representing different land cover types.

\section{E. MODIS LAI/FPAR Algorithm}

Large-scale ecosystem modeling is used to simulate a range of ecological responses to changes in climate and chemical 
composition of the atmosphere, including changes in the distribution of terrestrial plant communities across the globe in response to climate changes. LAI is a state parameter in several models describing the fluxes of energy, mass (e.g., water and $\mathrm{CO}_{2}$ ), and momentum between the surface and the planetary boundary layer. Variables that describe vegetation canopy structure and its energy absorption capacity are required by several of the EOS Interdisciplinary Projects [59]. The MODIS LAI/FPAR products use canopy radiation models for the retrieval of LAI and FPAR from surface reflectance measurements.

To estimate the canopy radiation regime, the following three important features must be carefully formulated:

1) architecture of individual trees and the entire canopy;

2) optical properties of vegetation elements (leaves, stems, etc.) and soil; the former depends on physiological conditions (water status, pigment concentration, etc.); and

3) atmospheric conditions that determine the incident radiation field.

For MODIS LAI/FPAR, we use a 3-D radiative transfer model [60] to derive simple spectral and angular biomespecific signatures of vegetation canopies and the above mentioned variables [61], [62]. However, these relationships are not used directly to obtain the best fit with measured spectral and angular characteristics of vegetation canopies. Accounting for features specific to the problem of radiative transfer in plant canopies, we adapt techniques used in other fields of physics for our retrieval algorithm [63], [64]. Allowing us to explicitly separate the contribution of ground reflectance to the observed radiances as well as to split a complicated radiative transfer problem into several independent and simpler subproblems, the solutions of which are stored in the form of LUT which are then used to retrieve LAI and FPAR.

The solutions of these subproblems are components of various forms of the energy conservation law (e.g., canopy transmittance and absorptance of a vacuum-bounded vegetation canopy). They are determined from general properties of radiative transfer and are independent of the models used to generate the LUT. Thus, we express the angular and spectral signatures of vegetation canopies in terms of an energy conservation law. Our algorithm is designed to return values of LAI and FPAR that provide the best agreement with the measured data and the energy conservation law. Since the algorithm interacts only with the elements of the LUT, its functioning does not depend on any particular canopy radiation model. This flexible feature allows the use of the best canopy model for the generation of the LUT.

Experimental data required to validate the model are those related to the incident radiation field, canopy structure. leaf and soil spectral optical properties, and canopy transmittance and reflectance. By comparing simulation results with measured data, we can determine the applicability of a canopy radiation model for generating the LUT [59], [65]. With the LUT generated using the verified model, test products can be validated with data from prelaunch field campaigns. Although the proposed algorithm uses the physics of radiation transfer in vegetation media, it has not been used in conjunction with satellite data before, therefore, a simple backup algorithm that uses NDVI-LAI and NDVI-FPAR relations, specific to landcovers, sun angles, and background brightness has also been implemented. This latter algorithm has been tested with multiyear AVHRR data to produce global fields of LAI (Fig. 7) and FPAR (Fig. 8).

\section{F. Fire Products}

The MODIS fire products consist of data sets at different spatial and temporal resolutions designed to meet the needs of the global change research community. The targeted users include ecologists, atmospheric chemists, and global modelers concerned with the fire emissions of gases and particulates, the impact of fire as a vegetation disturbance regime and the contribution of fire to biogeochemical cycles [66], [67]. The products will provide information on the distribution of fires and their frequency and timing, information pertaining to the emissions from the fires, and the area burned. The active fire products will be generated shortly after launch, the burned area products are planned for release one year later.

The MODIS fire algorithms are based on experience gained using the AVHRR sensor and the development of the IGBPDIS Global Fire Product [68]-[71]. In summary, the difference in response between the 3.9- and $11-\mu \mathrm{m}$ channels are used to identify fires and the temperatures of surrounding pixels are used to determine the background surface temperature of the active fire pixel. The sensitivity of the MODIS detectors to high-temperature sources will lead to improved detection and characterization over the AVHRR. The 10:30 a.m./p.m. overpass of the first MODIS will result in a sampling of the diurnal cycle of fire activity, which in some areas may be suboptimal for detecting active fires. The addition of the $2: 30$ a.m./p.m. observations from the MODIS EOS-PM1 instrument will provide a more comprehensive fire monitoring system.

In the postlaunch period, a new algorithm will be tested that will provide an estimation of the emitted energy. This algorithm uses a relationship between emitted energy from a fire and the sensor response at $3.9 \mu \mathrm{m}$. A full description of the MODIS active fire algorithms is provided by Kaufman et al. [71].

AVHRR 1-km data are currently being used to test a MODIS postlaunch burn scar product. The methodology will necessarily be multitemporal because of intrinsic surface variations and the low probability of daily cloud-free observations. Burn scars evolve and revegetate at differing rates in different biomes and climatic regimes. Burn scars are identified by the contrast between preburn and postburn reflectances, as portrayed by composited data. The output of the MODIS active fire product will also be used in the burn scar procedure to help identify burned pixels.

The reflective component of the $3.9 \mu \mathrm{m}$ is currently being evaluated as the primary burn scar indicator [72], [73]. The reflective component of the mid-IR may be extracted by using a variety of techniques and is less sensitive to scattering by smoke aerosols than shorter wavelengths, but it is sensitive to the presence of water at the surface [74], [75]. 


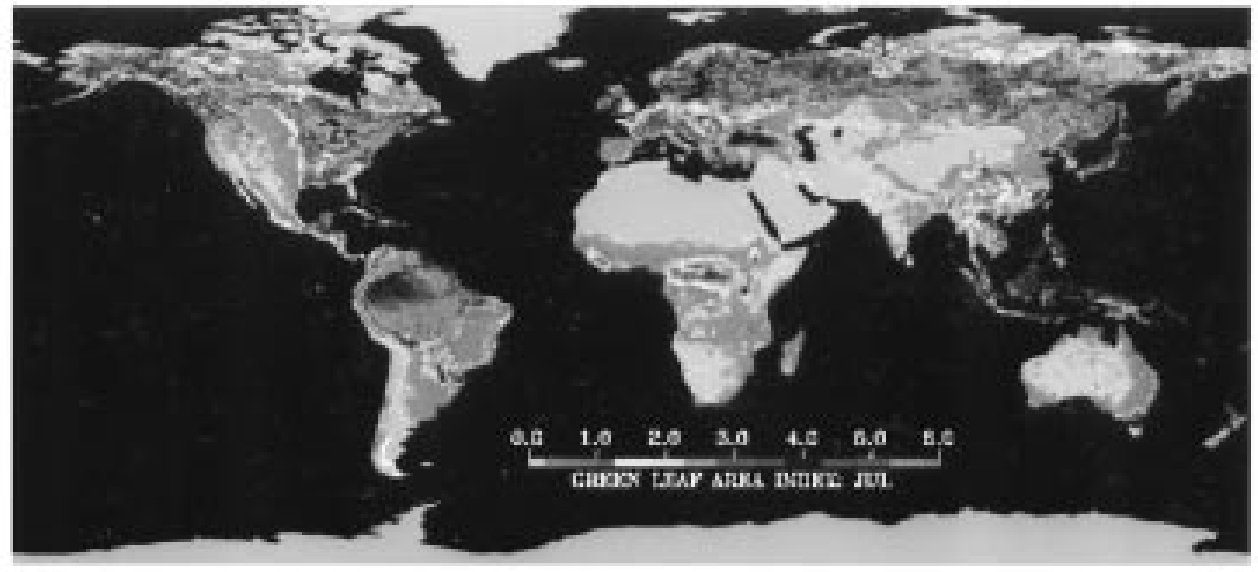

Fig. 7. Global LAI estimated with the MODIS at-launch algorithm. NDVI-LAI relationships were derived from the radiative transfer model and applied to the AVHRR Pathfinder NDVI data set. The land-cover-specific relations were applied to the ten-day composite NDVI data, and the resulting LAI values were averaged to obtain monthly LAI at the $8-\mathrm{km}$ native resolution of the Pathfinder data and then aggregated to a $0.25^{\circ}$ linear lat-long projection. This was done for all years from 1982 to 1990. The panel shows the color-coded image of LAI in July obtained by further averaging over the nine-year period of record. Areas colored white denote either missing data (terminator effect) or where the algorithm failed.

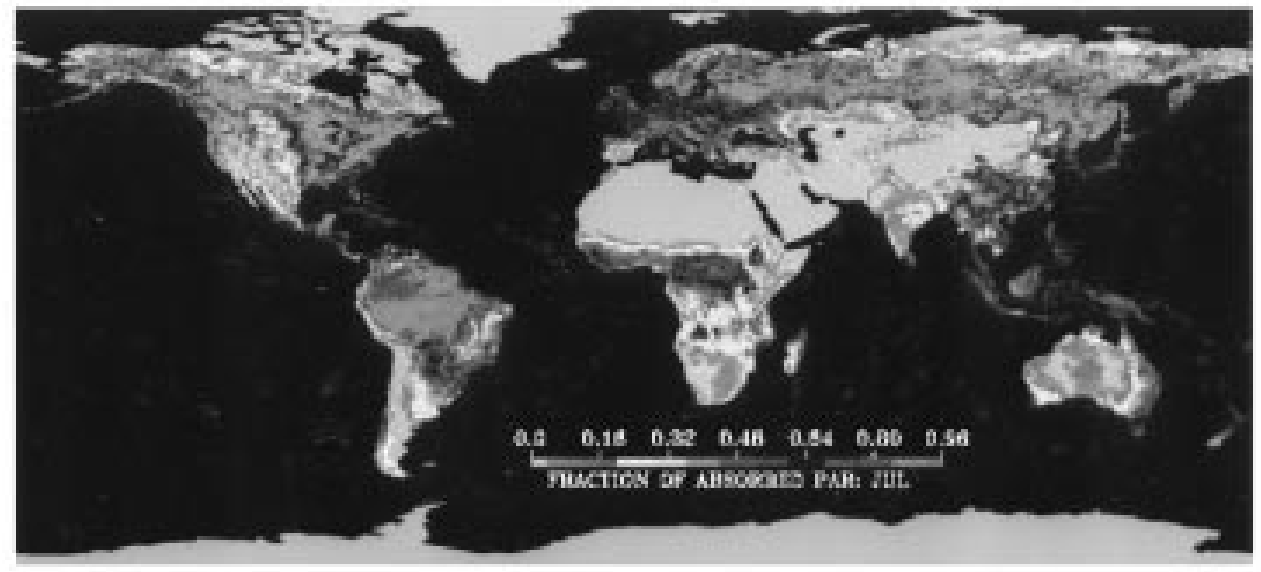

Fig. 8. Fraction of photosynthetically active radiation (FPAR) absorbed by green vegetation estimated with the MODIS backup algorithm. NDVI-FPAR relationships were derived from the radiative transfer model and applied to the AVHRR Pathfinder NDVI data set. The land-cover-specific relations were applied to the ten-day composite NDVI data, and the resulting FPAR values were averaged to obtain monthly FPAR at the 8-km native resolution of the Pathfinder data and then aggregated to a $0.25^{\circ}$ linear lat-long projection. This was done for all years from 1982 to 1990 . The panel shows the color-coded image of FPAR in July obtained by further averaging over the nine-year period of record. Areas colored white denote either missing data (terminator effect) or where the algorithm failed.

Fig. 9 shows AVHRR 1-km NDVI and Channel 3 (3.7 $\mu \mathrm{m})$ VI (VI3) maps computed over an active burn near the Okavango Delta, southern Africa. The VI3 is computed as with the NDVI, but with substitution of the red reflectance with the reflective component of the mid-IR [74]. The output of the most recent fire algorithm [68] is shown superimposed on the NDVI image.

\section{G. Snow, Lake Ice, and Sea Ice Cover}

Algorithms are under development to map global snow cover (including ice on large, inland lakes), sea ice cover, and sea ice surface temperature (IST) using MODIS data [76]. The L2 snow and sea ice products represent images of 500-m spatial resolution snow or 1-km spatial resolution sea ice at the time of data acquisition. The L3 products (digital maps gridded to a map projection) will provide daily and eightday composites of global snow and lake ice cover at 500-m resolution, and sea ice cover and IST at $1-\mathrm{km}$ resolution. Statistics will be provided regarding the extent and persistence of snow and ice cover at each grid cell for the Level-3 products. CMG products at quarter degree resolution are also under development. The snow and ice products are intended for climatologists and modelers as input to hydrological, sea ice, and general circulation models. For example, using the Regional Atmospheric Modeling System (RAMS) [77], snow melt rates can be generated by snow-melt routines with snow extent data from the MODIS snow maps. For sea ice, the MODIS IST product can be used in energy-balance models to provide an estimate of the energy flux between the ocean and the atmosphere. IST is calculated using a split-window technique [86]. The anticipated accuracy for the IST is in the range of $0.3-2.1 \mathrm{~K}$.

The MODIS snow data are also likely to be used by agencies, such as the NOAA Operational Hydrologic Remote 


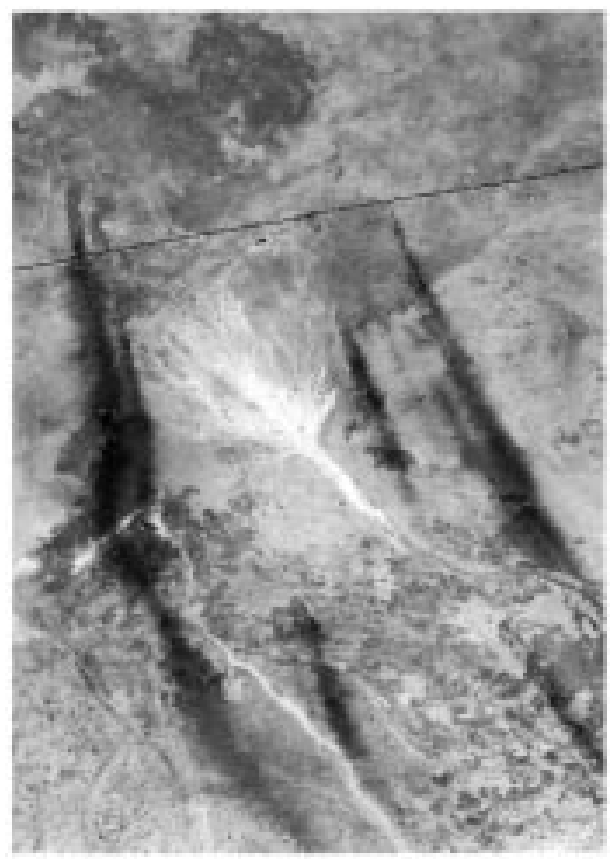

(a)

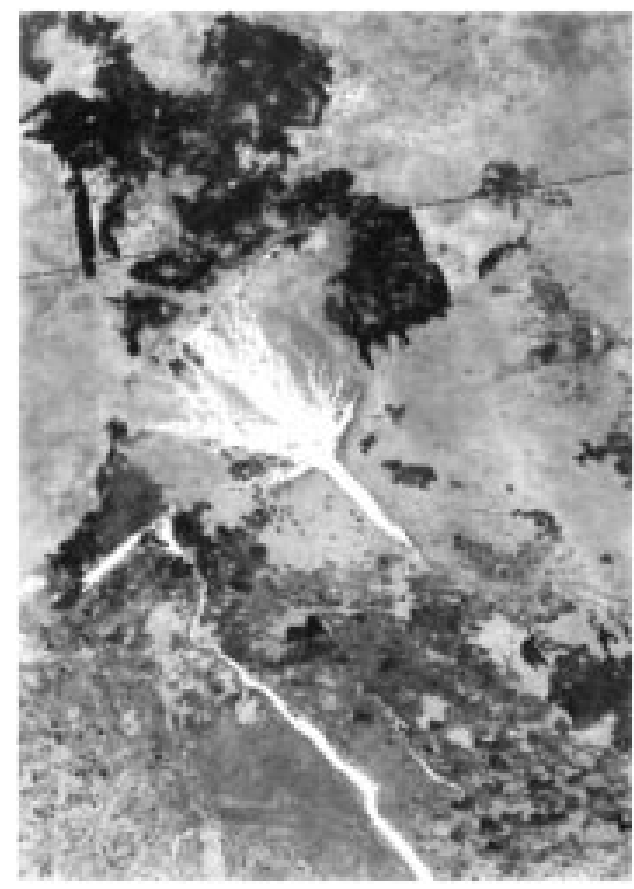

(b)

Fig. 9. Area of biomass burning near the Okavango Delta, Botswana, South Africa, depicted by NOAA-11 AVHRR local area coverage data $(1.1 \mathrm{~km}$ at nadir pixels) September 6, 1989. (a) NDVI: red indicates the positions of the detected active fires evident at origins of the smoke plumes and burn scar edges. (b) VI3: burn scars darker (lower moisture and vegetation cover) than the surrounding savanna. Smoke plumes evident in the NDVI image more than $500-\mathrm{km}$ long and largely unseen in the VI3 image, which shows considerably stronger discrimination between the burned and unburned areas.

Sensing Center (NOHRSC) [78], for use in existing regional snow-cover mapping projects. The MODIS-derived maps will enable study of long-term trends in snow, lake ice, and sea ice extent and duration, in conjunction with the available records of snow and ice extent produced by NOAA's National Envi-

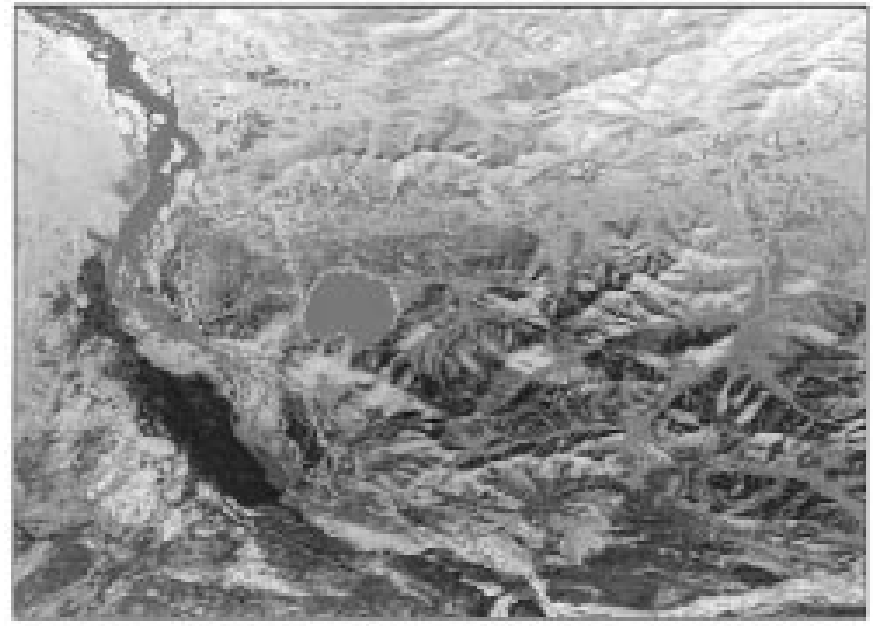

(a)

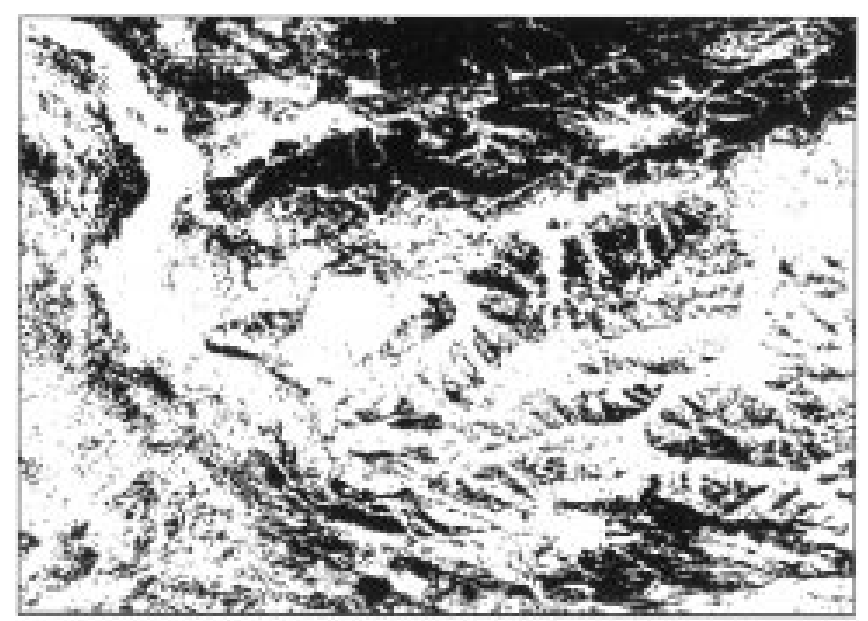

(b)

Fig. 10. MAS false-color image of an area southeast of Fairbanks, Alaska, acquired on April 13, 1995. MAS channels $1(0.527-0.571 \mu \mathrm{m})$, $7(0.848-0.891 \mu \mathrm{m})$, and $10(1.582-1.635 \mu \mathrm{m})$ were used to generate the color composite. Harding Lake is visible in the image. The result of the MODIS snow-mapping algorithm is shown in black and white, where white is snow-covered area and black is non-snow-covered area.

ronmental Satellite Data and Information Service (NESDIS) since 1966 [79].

The snow- and sea ice-mapping algorithms employ criteria to identify and classify snow and ice by reflective characteristics, and by temperature for sea ice, on a pixel-by-pixel basis [80] (Fig. 10). The MODIS 858-nm, 555-nm, and $1.63-\mu \mathrm{m}$ bands are used to map snow and ice, and the 11.00- and 12.1$\mu \mathrm{m}$ bands are used to calculate IST. In addition, NDVI data may be used in conjunction with the MODIS snow index to improve snow mapping in forested areas. MODIS L1B, a 1-km resolution land/water mask, and the MODIS cloud mask are used in the snow product production. A key criterion in the identification of snow and sea ice is the normalized difference snow index (NDSI). The usefulness of the NDSI is based on the fact that snow and ice are considerably more reflective in the visible than in the shortwave IR part of the spectrum, where the reflectance of snow drops to near-zero values. On 

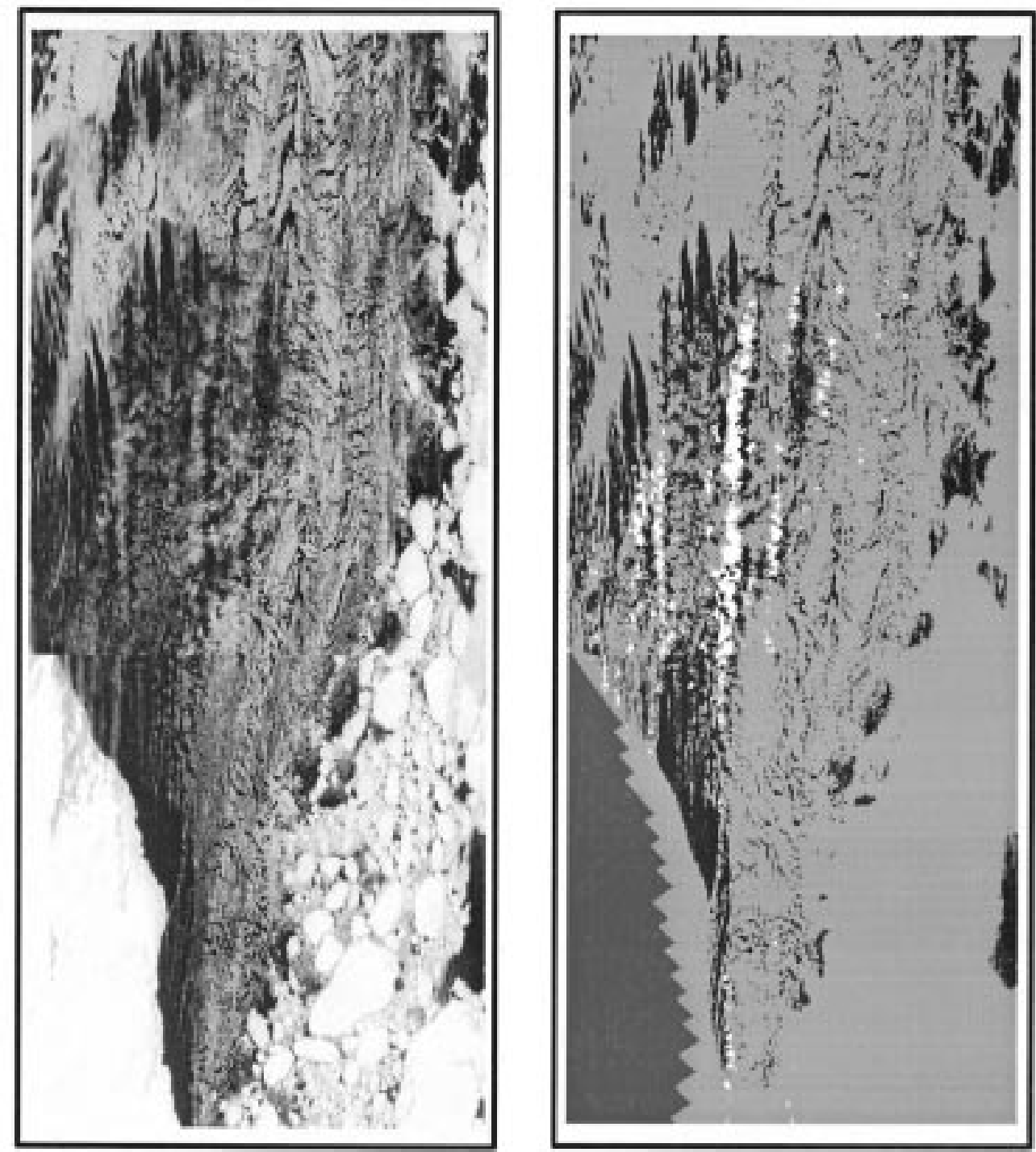

Fig. 11. MAS false-color image (left) of sea ice, water, and clouds, acquired on April 8, 1995, over the Bering Sea near St. Lawrence Island, AK. MAS channels $1(0.527-0.571 \mu \mathrm{m}), 7(0.848-0.891 \mu \mathrm{m})$, and $10(1.582-1.635 \mu \mathrm{m})$ were used to generate the color composite. The sea ice map (right) was generated by the ice-mapping algorithm from the false-color image; sea ice is shown in orange, clouds are in white, and land (St. Lawrence Island) is in green.

the other hand, reflectance of most clouds remains high in the shortwave IR.

Sea ice is identified by reflective characteristics using criteria tests and logic similar to the snow algorithm [81] (Fig. 11). Sea ice extent is determined in two ways: by reflective characteristics and by IST. The sea ice product contains two maps of sea ice extent, one for each method of determination. Sea ice types may be classified based on reflective features or on temperature. Classification of sea ice types is being investigated with MAS data with the possibility that a sea ice classification may be integrated into the MODIS sea ice data product.

Algorithm testing has been undertaken by aircraft and field experiments in forested areas of Montana, Saskatchewan, Alaska and New England and over prairies in Montana, tundra in Alaska, agricultural areas in Wisconsin, and over sea ice in the Bering and Beaufort Seas off the coast of Alaska. Additional campaigns are planned to validate the snow maps using ground and aircraft data in the postlaunch time frame. The snow-mapping algorithm has been run on more than 30 Landsat TM scenes and on a number of MAS scenes. Applying a prototype snow-mapping algorithm to an example TM scene of the snow-covered Sierra Nevada Mountains, CA, yielded a $>95 \%$ accuracy in mapping snow cover for pixels that contain about $50 \%$ or more snow cover when compared with results of snow mapping conducted using a thresholding and spectral-mixture modeling technique and field and aircraft observations [82].

The MODIS snow and ice data products will be validated in relationship to EOS and non-EOS snow data sets as well as ground observations using aircraft and field campaigns. Postlaunch validation of river-basin scale areas will employ Landsat-7 Enhanced Thematic Mapper plus (ETM+) and EOS Advanced Spaceborne Thermal Emission and Reflection Radiometer (ASTER) data and NOHRSC snow maps. For postlaunch validation at the hemispheric scale, NOAA/NESDIS 
TABLE IV

Land Cover and Land Cover Change Products

\begin{tabular}{l|l|l|l|l}
\hline Product & $\begin{array}{l}\text { Spatial } \\
\text { Resolution }\end{array}$ & $\begin{array}{l}\text { Temporal } \\
\text { Resolution }\end{array}$ & Delivery & PI \\
\hline $\begin{array}{l}\text { Land Cover } \\
\text { (CMG) }\end{array}$ & $1 \mathrm{~km}$ & quarterly & June 1999 & Strahler \\
\hline Land Cover & $25^{\circ}$ & quarterly & June 1999 & Strahler \\
\hline $\begin{array}{l}\text { Land Cover } \\
\text { Change }\end{array}$ & $250 \mathrm{~m}$ & quarterly & June 1998 & Townshend \\
\hline $\begin{array}{l}\text { Land Cover } \\
\text { Change }\end{array}$ & $1 \mathrm{~km}$ & quarterly & Sept. 1999 & Strahler \\
\hline Land Cover & $1 \mathrm{~km}$ & $1 \mathrm{~km}$ yearly & Sept. 1999 & Townshend \\
\hline
\end{tabular}

snow and sea ice hemispheric-scale maps will be available for comparison. Advanced Microwave Scanner Radiometer (AMSR) derived snow and ice maps will be available in 2000 following the EOS-PM1 launch and will also be compared with the MODIS-derived snow and ice maps.

Accuracy of the MODIS snow maps varies with land-cover type. Preliminary results show consistently high accuracy (nearly 100\%) in tundra, prairie, and agricultural areas and variable and reduced accuracy in forested areas. Errors derived from field and aircraft measurements will be extrapolated to the global scale to gain quantitative insight into errors anticipated from using the MODIS snow-mapping algorithm. An error estimate, by month, will be made by determining errors in each of the different land covers, weighted by the percent of that particular land cover in the snow-covered areas globally. The 1-km Global Land Cover and Characterization Data Base, distributed by EDC in Sioux Falls, SD, is being used in the prelaunch time frame. Error estimates will be refined in the postlaunch time frame by using the MODIS at-launch and postlaunch land cover products.

Following the launch of the EOS-PM1 spacecraft, the potential exists for combining MODIS and AMSR data to generate an enhanced snow product. It is hoped that a product will be developed that will employ reflective and passive-microwave data to map snow extent and depth daily, irrespective of cloud cover and darkness.

\section{H. Land Cover/Land Cover Change Products}

Land cover maps are needed for global climate and ecosystem process models as well as to characterize the distribution and status of major land surface types for environmental and ecological applications. Land cover change analysis is required for monitoring the temporal dynamics and changes in land surface status. To meet these requirements, the MODIS Land Cover and Land Cover Change products include atlaunch and postlaunch products at $250-\mathrm{m}, 500-\mathrm{m}, 1000-\mathrm{m}$, and $.25^{\circ}$ resolutions, which are generally produced quarterly (see Table IV).

The primary land cover classification to be employed is that of the 17-class International Geosphere-Biosphere Programme (IGBP) classification scheme. The structural definition, development process, and functional flow of the MODIS Land Cover and Land Cover Change Products are described in the Algorithm Theoretical Basis Document (ATBD) [83].

The MODIS Land Cover product will be prepared by classification of multiple streams of MODIS Level-3 data products, ranging from BRDF-corrected surface reflectances to land surface temperature and spatial texture. The classifier algorithm will be either an advanced form of decision tree [84] or neural network [85], or possibly a hybrid of both. Recent tests with comparable data sets have shown that these classifiers are capable of very high accuracy when trained and then tested on unseen data. As a prototype, a classification of vegetation and land cover using 1-km composited AVHRR NDVI data was prepared for Central America based on 450 training sites derived from TM with validation by local experts and some field observations (Fig. 12) [86]. In the postlaunch era, additional land cover products will be tested, providing information, such as the proportion of woody cover or of deciduous vegetation (Fig. 13) [87].

Time-series data describing a cycle of vegetation phenology are required to derive the postlaunch land cover product. In the interim, while a stable time series of MODIS data is being developed and to fulfill the land cover needs of the other MODIS products, an at-launch land cover product will be derived from the AVHRR 1-km data. The at-launch product will contain the 17 IGBP classes, will be in the same format as the postlaunch product, and is likely to contain multiple layers with alternative land cover products.

Land cover change will be documented using two approaches. First, a fine-resolution $(250-\mathrm{m})$ land cover change alarm product will provide early warning that land cover change is occurring [83]. This algorithm is intended to detect abrupt land cover change induced by human activities, such as forest clearing and urbanization. The algorithm will use a combination of techniques to detect land cover change, including differences in local spatial texture between successive dates, appearance of linear features, differences in red and IR reflectances after compensation for seasonal differences, and the angle and magnitude of differences in reflectance. Second, as a postlaunch product, change induced primarily by interannual variability in climate, will be quantified at $1-\mathrm{km}$ spatial resolution using a multitemporal change vector approach [88], [89]. The magnitude of the change vector and its direction in measurement space indicate the level and type of change. Tests on multiyear AVHRR composited NDVI data for Africa demonstrate the ability of the change vector technique to identify both permanent conversions and temporary modification in surface attributes produced by climatic variations [90].

\section{Net Photosynthesis/Net Primary Productivity}

Probably the single most fundamental measure of global change of highest practical interest to humankind is any change in terrestrial biological productivity. Daily net photosynthesis (PSN) is the total of photosynthesis minus all autotrophic respiration over a $24-\mathrm{h}$ period. Net primary production (NPP) is the annual sum of daily PSN. These products will have both theoretical and practical utility. The theoretical use is primarily for defining the carbon balance for terrestrial surfaces in the context of global carbon cycle studies. The practical utility of a PSN/ NPP product is as a measure of crop yield, range forage and forest production, and other economically and socially significant products of vegetation growth. 


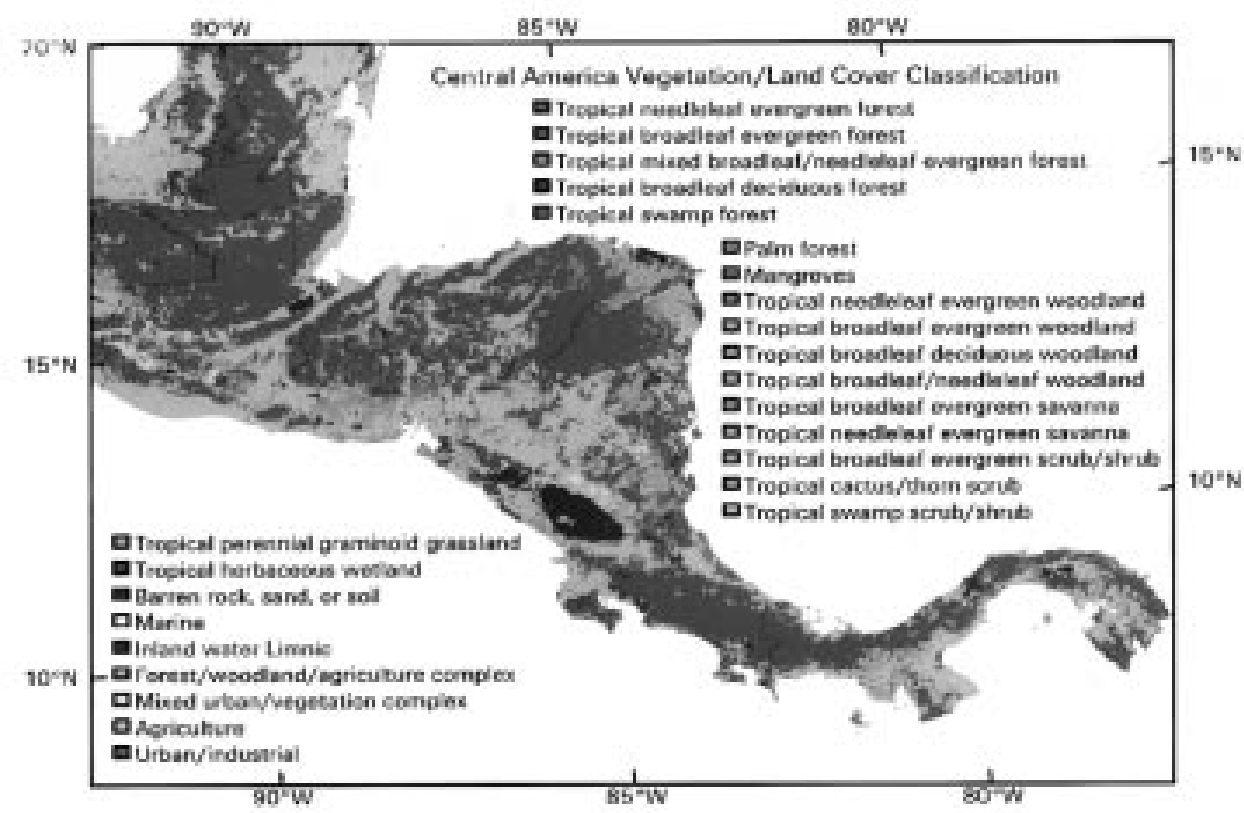

Fig. 12. Land cover map of Central America derived using the proposed at-launch MODIS Land Cover algorithm.

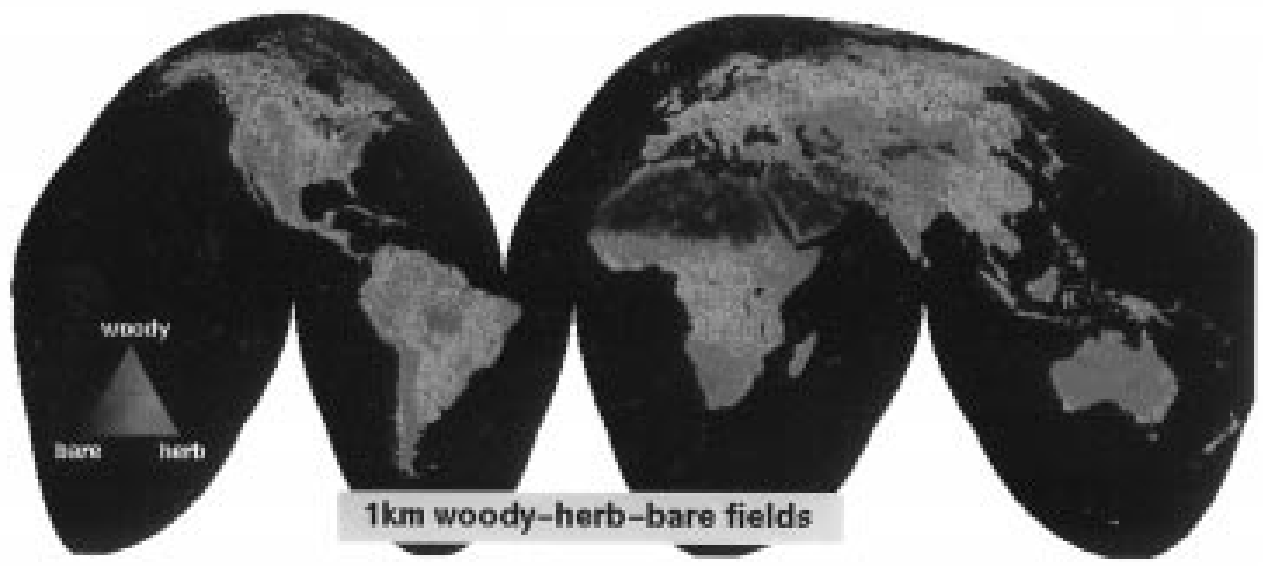

Fig. 13. Representation of land cover as continuous proportions of ground components based on data from the AVHRR.

PSN/NPP are MODIS L4 products produced using MODIS LAI/FPAR, land cover, and daily Data Assimilation Office (DAO) climatology. A PSN product will be generated every eight days, while NPP will be produced once per annum [13].

The algorithms for these products are based on a model usually ascribed to Monteith [91], which relates PSN and NPP to the amount of absorbed photosynthetically active radiation (APAR). The ability to estimate APAR from satellite-based spectral vegetation indexes (SVI) allows us now to estimate PSN/NPP at global scales [92] (Fig. 14). To implement the algorithms, ancillary data on climate and incident photosynthetically active radiation (PAR) and MODIS land cover type are required.

While FPAR and PAR can be routinely estimated from satellite data, accurate derivation of the PAR conversion efficiency (e) is difficult; therefore, it is the crux of this algorithm.
Variations in climate, such as temperature, humidity, and soil water, as well as biological differences, such as land cover type and physiological differences between $C 3$ and $C 4$ plants, produce large variations in conversion efficiency. To account for the biological variation, a simple biome classification scheme based on canopy structure and dynamics, which divides global vegetation into six classes (Grass, Broadleaf annuals, Evergreen Broadleaf, Evergreen Needleleaf, Deciduous Needleleaf, Deciduous Broadleaf), is used in this algorithm [93]. Furthermore, interactions of climate and vegetation and their influence on conversion efficiency have been explored using an ecosystem simulation model (BIOME-BGC). Sensitivity analysis addressing optimum temperatures for photosynthesis, variations in specific leaf area, and leaf nitrogen was used to generate values for an LUT for use in the algorithm. Autotrophic respiration (Ra) is estimated from carbon pools 


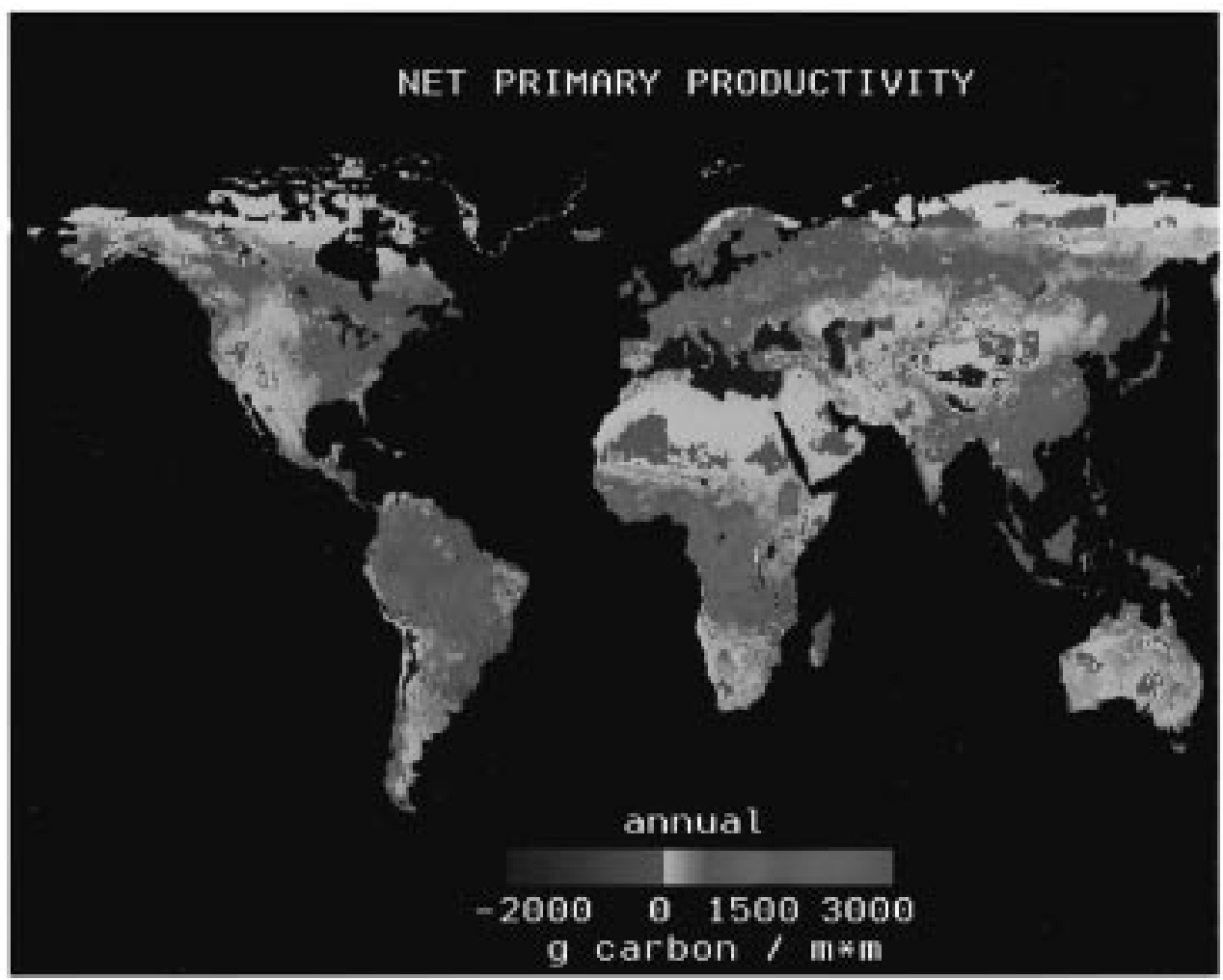

Fig. 14. Example of global NPP that will be produced from the MODIS NPP algorithm.

TABLE V

QA Information Stored for Every Pixel in All MODLAND Products and Summarized Over Every Modland Granule as Four QA Metadata, Indicating the Percentage of Pixels in the Granule with Each QA Code. Other QA Information Will Be Stored (See Text)

\begin{tabular}{l|l}
\hline Per Pixel QA Code & Meaning \\
\hline 00 & $\begin{array}{l}\text { Pixel produced, good quality, not } \\
\text { necessary to examine more detailed } \\
\text { QA }\end{array}$ \\
\hline 01 & $\begin{array}{l}\text { Pixel produced, unreliable or } \\
\text { unquantifiable quality, recommend } \\
\text { examination of more detailed QA }\end{array}$ \\
\hline 10 & $\begin{array}{l}\text { Pixel not produced due to cloud } \\
\text { effects. }\end{array}$ \\
\hline 11 & $\begin{array}{l}\text { Pixel not produced primarily due to } \\
\text { reasons other than cloud. }\end{array}$ \\
\hline
\end{tabular}

in stems, leaves, and roots derived using LAI and land cover type in various climate zones.

The ability of these algorithms to estimate PSN and NPP will depend on the accuracy of the computation of conversion efficiency and the spatial and temporal accuracy of the MODIS FPAR and LAI products. Validation of PSN/NPP products is extremely difficult at MODIS scales. However, a number of efforts are underway using $\mathrm{CO}_{2}$ flux towers in Europe and North America and through the compilation of field data by the IGBP [94].

\section{MODIS DATA QUALITY AND VALIDATION}

The EOS Data Information System (EOSDIS) will provide the computing and network facilities to support the EOS activities, including processing, distributing, and archiving EOS data, exchanging results among scientists, and commanding and controlling the spacecraft instrumentation. The EOSDIS Core System (ECS) will provide the computing architecture needed to accomplish these goals [95]. The quality of EOS data products will be maintained through instrument calibration and characterization and quality assurance and validation activities.

\section{A. MODIS Quality Assessment}

The objective of MODLAND QA is to identify and flag suspect and poor-quality data before their release to the public. This task is challenging for MODLAND because of the numerous error sources that may affect the data quality, because of the large volume of data products and the data dependencies that exist between them, and because different spatial and temporal samples of data must be examined. Sources of potential error include inadequacies in the robustness of the algorithm or the processing code used to make the products, operational data production, archival and dissemination errors, and errors that may be caused by the MODIS instrument, the satellite platform and the satellite-to-ground station data transmission.

The MODLAND approach is to coordinate the storage of QA results in all MODLAND products, the capability to infer which products are suspect, the extraction of these products from the data archive for detailed postproduction QA, and the subsequent storage of postproduction QA results. EOS data will be made available soon after production, necessitating that most QA is performed automatically by the processing software and only limited QA is performed after production has occurred. Postproduction QA will be undertaken informally by the MODLAND science team at their own institutions and 
TABLE VI

MODLAND HieraRchical Test Site SCHEME

\begin{tabular}{l|l|l|l|l}
\hline Tier & $\begin{array}{l}\text { Approx. } \\
\text { Number of Sites }\end{array}$ & Sample Area $\left.\mathbf{( k m}^{2}\right)$ & Description of Instrumentation and Sampling & Example Sites/ Networks \\
\hline $\begin{array}{l}\text { 1 Intensive Field Campaign } \\
\text { Sites; International Field } \\
\text { Campaign Programs }\end{array}$ & 5 & 1000 & $\begin{array}{l}\text { Intensive sampling of all relevant land and } \\
\text { atmospheric parameters, including boundary layer } \\
\text { gas exchange; often over land cover gradients }\end{array}$ & $\begin{array}{l}\text { FIFE, BOREAS, } \\
\text { HAPX-Sahel, TRACE-A, } \\
\text { SAFARI 2000, LBA }\end{array}$ \\
\hline 2 Fully Instrumented Sites & 5 & 100 & $\begin{array}{l}\text { Full suite of radiation and flux measurements; } \\
\text { ground, tower, and aircraft measurements }\end{array}$ & ARM/CART sites \\
\hline 3 Biome Tower Sites & $20-30$ & 100 & $\begin{array}{l}\text { Long-term, select instrument packages for } \\
\text { process studies; ground and tower measurements; } \\
\text { all major ecosystems and climatic regions }\end{array}$ & $\begin{array}{l}\text { Harvard Forest-Temperate } \\
\text { Deciduous Forest Site }\end{array}$ \\
\hline $\begin{array}{l}\text { 4 Globally Distributed Test } \\
\text { Sites }\end{array}$ & 60 & $\begin{array}{l}\text { Limited surface and atmospheric characterization; } \\
\text { select instrument suites at different sites; widely } \\
\text { distributed variable sampling frequencies } \\
\text { (intermittent to continuous) capture seasonal or } \\
\text { interannual variability, climatology; permanent } \\
\text { sites }\end{array}$ & $\begin{array}{l}\text { LSRN, and SURFRAD } \\
\text { networks }\end{array}$ \\
\hline $\begin{array}{l}\text { 5 Instrument Calibration } \\
\text { Sites }\end{array}$ & $<5$ & $\begin{array}{l}\text { Well-instrumented for vicarious calibration; } \\
\text { unique reflectance and emittance properties of } \\
\text { uniform, typically nonvegetated surfaces; ground } \\
\text { and aircraft measurements may include geometric } \\
\text { calibration site(s) }\end{array}$ & White Sands, Railroad Playa \\
\hline
\end{tabular}

routinely on a sample of all MODLAND products by a small cadre of scientific and technical staff at a centralized Land Data Operational Product Evaluation (LDOPE) facility.

ECS provides for the storage of per pixel QA results and QA metadata for each MODIS data granule. A granule corresponds to approximately 5 min of MODIS observations and covers an area of approximately $2340 \times 2000 \mathrm{~km}$. MODLAND per pixel QA results will be derived in the processing software by monitoring the computational stability of the code, examination of the input data and its associated QA data, and documentation of the code processing history. QA metadata will summarize the application of production and postproduction QA procedures. QA metadata written during production will include granule-level summaries of the per pixel QA results and an automatic quality flag set as "passed," "suspect," or "failed." Postproduction QA results will be stored in the quality flag metadata. To enable consistent interpretation across all MODLAND products, two generic QA bits will be stored per pixel and will be summarized over each granule as four QA metadata (Table V). Additional product-specific QA information will be stored at the discretion of the science team.

MODLAND postproduction QA procedures will be applied to granules that have suspect or poor quality, indicated by the QA metadata, regular samples of all MODLAND products, and specific granules to evaluate suspected problems. Granules will be obtained from the ECS data archive using a subscription client to order data as it is produced and a data order client to order existing data. A hierarchy of QA procedures, including visualization, knowledge-based trending, and statistical analysis procedures will be applied to the granules. Postproduction QA results will be stored in the quality flag metadata to indicate that the granule is "being evaluated," or has "passed" or "failed" a specified postproduction QA procedure. The quality flag has a default value "of not investigated." After the initial postlaunch period, the LDOPE personnel will relieve the science team of the burden of routine QA and attempt to examine up to $10 \%$ of the daily averaged MODLAND data production.

It is recognized that some of the products are new and that, consequently, QA procedures and indicators of product quality will change as the science team and the user community learn more about their characteristics and the performance of the algorithm and the instrument. MODLAND QA procedures are currently being tested using simulated MODIS data and multitemporal AVHRR data sets.

\section{B. Validation Approach}

MODLAND's primary validation objective is to assess its L2-4 products. To accomplish this, they will use a variety of validation methods, including product comparisons with insitu data collected over a distributed set of validation test sites, comparisons with data and products from other airborne and spaceborne sensors, analysis of trends in the data, and analysis of process model results that are driven or constrained by the products. Although comprehensive validation will ultimately be achieved in concert with the broader community, the following section describes the activities and current plans of the MODLAND team.

MODLAND has developed a multitiered validation strategy to provide measurements over the range of the earth surfaceatmosphere systems and at resolutions commensurate with MODIS pixels ( $250 \mathrm{~m}-1 \mathrm{~km}$, or larger). Central to this plan is a five-tiered test site scheme, developed after the hierarchical observation scheme proposed by the Terrestrial Observation Panel for Climate (TOPC) of the Global Climate Observing System (GCOS). Table VI describes the MODLAND tiers and provides examples. This categorization provides an inverse degree of measurement intensity per-site, with a number of sites in the tier. Thus, MODLAND will rely on few intensive field campaigns, but a large number of sites for which only higher resolution satellite scenes and/or limited field data collection are regularly available.

A core set of EOS Land Test Sites is being developed consisting of Tier 3 and 4 sites, which will act as a focus for field measurement activities [94]. Typically, these sites will feature a tower to provide year-round sampling of most radiometric products at a central point. These measurements 


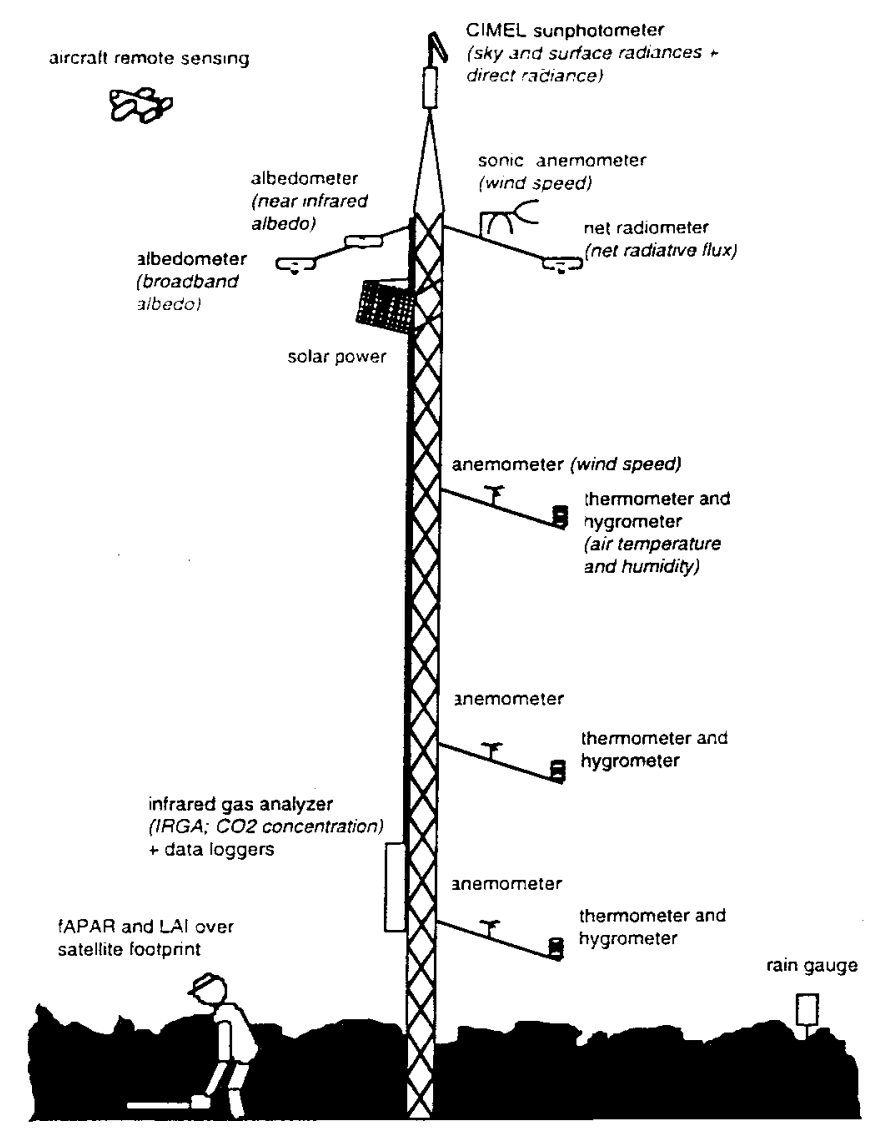

Fig. 15. Schematic of a MODLAND Validation Tier 3/4 tower site.

will be extrapolated to larger regions using ground and airborne remote-sensing transects e.g., with $10-100-\mathrm{km}$ radius of the site, depending on land cover heterogeneity. Sampling along the transects will occur episodically and more frequently during times of greater phenological change. These transects will also be used to measure and extrapolate biophysical variables, such as canopy structure, which cannot be measured from the towers. Fig. 15 depicts a typical tower configuration.

To provide prelaunch algorithm evaluation and to test Tier 3/4 validation methods, MODLAND team members conducted several preparatory field campaigns in 1997: the Winter Cloud Experiment (WINCE) campaign for snow and ice, the California and Western States (CALWEST) campaign to validate the LST algorithm, the Prototype Validation Exercises (PROVE) to test instrumentation and sampling strategies over a desert grassland in New Mexico, and mixed forest near Oak Ridge, TN. Significant emphasis has been placed on product scaling using the remote-sensing data acquired from aircraft, AVHRR, GOES, POLDER, TM, and SPOT during the campaigns.

As part of the EOS Validation program, MODIS plans to make its validation data sets available to the public through the World Wide Web; the 1997 campaigns are described at URL: http://pratmos.gsfc.nasa.gov/ justice/modland/valid /index.html.

\section{CONCLUSION}

This paper has provided an overview of the current focus of MODIS land-discipline activities. Preparation for MODIS represents an unprecedented effort by part of the land remote- sensing community to take research algorithms and transform them to operational processing code to generate highorder data products. There is expectation of considerable improvement over existing data sets. For example, marked improvements are anticipated in spatial resolution, spectral band location, and calibration as compared to the AVHRR.

The EOS Pathfinder experience has helped in the design of the MODIS data products [96]. One key lesson from Pathfinder is that the scientific user community has a preference for higher order data products. Atmospherically corrected, standard temporal composites, or spatially aggregated data sets reduce the burden of data processing on the user, thus, enabling resources of individual scientists to be focused on answering the science questions rather than data processing. This will be particularly important in light of the high data volumes associated with MODIS.

The strength of coarse and medium resolution remote sensing lies in the multitemporal information it provides. A stable, well-calibrated time series is essential. The AVHRR Global Area Coverage (GAC) time series has undergone three major reprocessings as algorithms and calibration have been refined [7]. Multiple reprocessing of MODIS data sets is essential in the planning of the EOS computational resources. The value of the MODIS data stream will be in part dependent on its use within the context of precursor data sets so that trends and change can be understood within a longer time scale. It will be important to provide compatibility and overlap between existing data sets and MODIS products.

The availability of MODIS data products to the user will be a function of the instrument performance, robustness of the algorithms and associated production code, functionality and operational readiness of the EOS ECS, and capacity of the EOS DAAC's to distribute data. The performance of the EOS will be judged by the amount and quality of data it provides. Currently, as part of a cost-cutting initiative, the MODIS team is being asked to develop a plan for producing only $25 \%$ of the L2-4 products in the first six months after launch, rising to $100 \%$ of the planned data volume after three years.

The MODIS land team is preparing to provide some important data sets with the hope that once they have been validated and their utility demonstrated, they will be adopted as standard products for future operational satellites and provide the basis for long-term monitoring. It is encouraging that some of the characteristics of the MODIS land products are being incorporated into future moderate-resolution sensing systems, such as the Japanese Global Land Imager (GLI) and the United States NPOESS.

\section{ACKNOWLEDGMENT}

The authors would like to thank all those who have contributed to the MODLAND group effort by providing the development and coding of algorithms, L. Fishtahler for providing the information on MODIS volumes and loads, D. Witczak for editorial support, and J. Kendall and S. Korontzi for help with the figures. 


\section{REFERENCES}

[1] W. L. Barnes, T. S. Pagano, and V. V. Salomonson, "Prelaunch characteristics of the Moderate Resolution Imaging Spectroradiometer (MODIS) on EOS-AM1," this issue, pp. 1088-1100.

[2] Y. Yamaguchi, A. B. Kahle, H. Tsu, K. Kawakami, and M. Pniel, "Overview of Advanced Spaceborne Thermal Emission and Reflection Radiometer (ASTER)," this issue, pp. 1062-1071.

[3] D. J. Diner, J. C. Beckert, T. H. Reilly, C. J. Bruegge, J. E. Conel, R. A. Kahn, J. V. Martonchik, T. P. Ackerman, R. Davies, S. A. W. Gerstl, H. R. Gordon, J.-P. Muller, R. B. Myneni, P. J. Sellers, B. Pinty, and M. M. Verstraete, "Multi-angle Imaging SpectroRadiometer instrument description and experiment overview," this issue, pp. 1072-1087.

[4] B. A. Wielicki, B. R. Barkstrom, B. A. Baum, T. P. Charlock, R. N Green, D. P. Kratz, R. B. Lee, III, P. Minnis, G. L. Smith, T. Wong, D. F. Young, R. D. Cess, J. A. Coakley, Jr., D. A. H. Crommelynck, L. Donner, R. Kandel, M. D. King, A. J. Miller, V. Ramanathan, D A. Randall, L. L. Stowe, and R. M. Welch, "Clouds and the Earth's Radiant Energy System (CERES): Algorithm overview," this issue, pp. $1127-1141$

[5] C. O. Justice, J. R. G. Townshend, B. N. Holben, and C. J. Tucker, "Analysis of the phenology of global vegetation using meteorological satellite data," Int. J. Remote Sensing, vol. 6, pp. 1271-1318, 1985.

[6] C. J. Tucker, I. Y. Fung, C. D. Keeling, and R. H. Gammon, "The relationship between atmospheric $\mathrm{CO}_{2}$ variations and a satellite-derived vegetation index," Nature, vol. 319, pp. 195-199, 1986.

[7] C. J. Tucker, H. E. Dregne, and W. W. Newcomb, "Expansion and contraction of the Sahara Desert from 1980-1990," Science, vol. 253, pp. 299-301, 1991

[8] C. O. Justice and J. R. G. Townshend, "Data sets for global remote sensing: Lessons learned," Int. J. Remote Sensing, vol. 15, no. 17, pp. 3621-3639, 1994

[9] J. R. G. Townshend, "Global data sets for land applications for the advanced very high resolution radiometer: An introduction," Int. J. Remote Sensing, vol. 11, pp. 51-54, 1994.

[10] P. J. Sellers, C. J. Tucker, G. J. Collatz, S. Los, C. O. Justice, D. A. Dazlich, and D. A. Randall, "A global $10 * 10$ NDVI data set for climate studies. Part 2-The adjustment of the NDVI and generation of global fields of terrestrial biophysical parameters," Int. J. Remote Sensing, vol 15, pp. 3519-3545, 1994.

[11] R. B. Myneni, C. D. Keeling, C. J. Tucker, G. Asrar, and R. R. Nemani, "Increased plant growth in the northern high latitudes from 1981-1991," Nature, vol. 386, pp. 698-702, 1997.

[12] D. S. Skole, C. O. Justice, A. Janetos, and J. R. G. Townshend, "A land cover change monitoring program: a strategy for international effort," Mitigation and Adaptation Strategies for Global Change. Amsterdam, The Netherlands: Kluwer, 1997, pp. 1-19.

[13] S. W. Running, C. O. Justice, V. V. Salomonson, D. K. Hall, J. Barker, Y. J. Kaufman, A. R. Strahler, J.-P. Muller, V. Vanderbilt, Z. Wan, P. Teillet, and D. Carneggie, "Terrestrial remote sensing science and algorithms planned for the MODIS-EOS," Int. J. Remote Sensing, vol. 15 , no. 17 , pp. $3587-3620,1994$

[14] A. C. Janetos, C. O. Justice, and R. C. Harriss, "Mission to planet earth: Land cover/land use change program," Biomass Burning and Global Change, J. Levine, Ed., vol. 1. Cambridge, MA: MIT Press, 1996, pp. 3-14.

[15] World Meteological Organization GCOS/GTOS Plan for Terrestrial Climate Related Observations. GCOS-32, WMO/TD No \#796, UNEP/DEIA/TR.97-7. Joint Planning Office, Geneva, Switzerland, 1997.

[16] B. Guenther, G. D. Godden, X. Xiong, E. J. Knight, S.-Y. Qiu, M. M. Hopkins, M. G. Khayat, and Z. Hao, "Prelaunch algorithm and data format for the Level 1 calibration products for the EOS-AM1 Moderate Resolution Imaging Spectroradiometer (MODIS)," this issue, pp. 1142-1151.

[17] E. Vermote and Y. J. Kaufman, "Absolute calibration of AVHRR visible and near infrared channels using ocean and cloud views," Int. J. Remote Sensing, vol. 16, no. 13, pp. 2317-2340, 1995.

[18] R. E. Wolfe, D. P. Roy, and E. Vermote, "MODIS land data storage, gridding, and compositing methodology: Level 2 grid," this issue, pp. 1324-1338.

[19] E. Masuoka, A. Fleig, R. E. Wolfe, and F. Patt, "Key characteristics of MODIS data products," this issue, pp. 1313-1323.

[20] E. Vermote, D. Tanré, J. L. Deuzé, M. Herman, and J. J. Morcrette, "Second simulation of the satellite signal in the solar spectrum: An overview," IEEE Trans. Geosci. Remote Sensing, vol. 35, pp. 675-686, May 1997.

[21] D. Tanré, M. Herman, and P. Y. Deschamps, "Influence of the back- ground contribution upon space measurements of ground reflectance," Appl. Opt., vol. 20, pp. 3673-3684, 1981

[22] Y. J. Kaufman, "Solution of the equation of radiative transfer for remote sensing over two-dimensional surface reflectivity," J. Geophys. Res., vol. 20, pp. 4137-4147, 1982.

[23] Y. Mekler and Y. J. Kaufman, "The effect of earth's atmosphere on contrast reduction for a nonuniform surface albedo and two-halves field," J. Geophys. Res., vol. 85, pp. 4067-4083, 1980.

[24] T. Y. Lee and Y. J. Kaufman, "Non-Lambertian effects on remote sensing of surface reflectance and vegetation index," IEEE Trans. Geosci. Remote Sensing, vol. GE-24, pp. 699-708, July 1986.

[25] E. Vermote, N. Z. El Saleous, C. O. Justice, Y. J. Kaufman, J. L. Privette, L. Remer, J. C. Roger, and D. Tanré, "Atmospheric correction of visible to middle infrared EOS-MODIS data over land surface, background, operational algorithm and validation," J. Geophys. Res., pp. 102, D14, 17, 131-17,141, 1997

[26] A. Fleig and K. Yang, "Description of the MODIS synthetic data-set," personal communication, 1995.

[27] Z. Wan and J. Dozier, "Land-surface temperature measurement from space: Physical principles and inverse modeling," IEEE Trans. Geosci. Remote Sensing, vol. 27, pp. 268-278, May 1989.

[28] _ "A generalized split-window algorithm for retrieving landsurface temperature from space," IEEE Trans. Geosci. Remote Sensing, vol. 34, pp. 892-905, July 1996.

[29] Z. Wan and Z. L. Li, "A physics-based algorithm for retrieving landsurface emissivity and temperature from EOS/MODIS data," IEEE Trans. Geosci. Remote Sensing, vol. 35, pp. 980-996, July 1997.

[30] W. Snyder and Z. Wan, "Surface temperature correction for active infrared reflectance measurements of natural materials," Appl. Opt., vol. 35, no. 13, pp. 2216-2220, 1996.

[31] W. Snyder, Z. Wan, Y. Zhang, and Y. Z. Feng, "Thermal infrared (3-14 micron) bidirectional reflectance measurements of sands and soils," Remote Sens. Environ., vol. 60, pp. 101-109, 1997.

[32] F. E. Nicodemus, J. C. Richmond, J. J. Hsia, I. W. Ginsberg, and T. Limperis, "Geometrical considerations and nomenclature for reflectance," Nat. Bur. Stand. Rep., vol. NBS MN-160, p. 52, 1977.

[33] M. Leroy, and J.-L. Roujean, "Sun and view angle corrections on reflectances derived from NOAA/AVHRR data," IEEE Trans. Geosci. Remote Sensing, vol. 32, pp. 684-697, May 1994.

[34] Z. Li, J. Cihlar, X. Zheng, L. Moreau, and H. Ly, "The bidirectional effects of AVHRR measurements over boreal regions," IEEE Trans. Geosci. Remote Sensing, vol. 34, pp. 1308-1322, Nov. 1996.

[35] J. K. Ross, The Radiation Regime and Architecture of Plant Stands. The Hague: Junk, 1981, p. 392.

[36] X. Li and A. H. Strahler, "Geometric-optical bidirectional reflectance modeling of the discrete crown vegetation canopy: Effect of crown shape and mutual shadowing," IEEE Trans. Geosci. Remote Sensing, vol. 30, pp. 276-292, Jan. 1992.

[37] A. Henderson-Sellers and A. J. Pitman, "Land-surface schemes for future climate models: Specification, aggregation, and heterogeneity," J. Geophy. Res., vol. 97, pp. 2687-2696, 1997.

[38] F. G. Hall, J. R. G. Townshend, and E. T. Engman, "Status of remote sensing algorithms for estimation of land surface parameters," Remote Sens. Environ., vol. 51, pp. 138-156, 1995.

[39] E. Vermote, N. Z. El Saleous, C. O. Justice, Y. J. Kaufman, J. L. Privette, L. Remer, J. C. Roger, and D. Tanre, "Atmospheric correction of visible to middle-infrared EOS-MODIS data over land surfaces: Background, operational algorithm and validation," J. Geophys. Res., vol. 102, pp. 17131-17142, 1997.

[40] Y.-C. Zhang, W. B. Rossow, and A. A. Lacis, "Calculation of surface and top of atmosphere radiative fluxes from physical quantities based on ISCCP data sets, 1, method and sensitivity to input data set uncertainties," J. Geophys. Res., vol. 100, pp. 1149-1165, 1995.

[41] W. Wanner, A. Strahler, B. Hu, P. Lewis, J.-P. Muller, X. Li, C. L. Barker Schaaf, and M. Barnsley, "Global retrieval of bidirectional reflectance and albedo over land from EOS MODIS and MISR data: Theory and algorithm," J. Geophys. Res., vol. 102, pp. 17 143-17 162, 1997.

[42] B. Hu, W. Lucht, X. Li, and A. H. Strahler, "Validation of kernel-driven models for global modeling of bidirectional reflectance," Remote Sens. Environ., vol. 62, pp. 201-214, 1997.

[43] J. L. Roujean, M. Leroy, and P. Y. Deschamps, "A bidirectional reflectance model of the earth's surface for the correction of remote sensing data," J. Geophys. Res., vol. 97, pp. 20455-20 468, 1992.

[44] W. Wanner, X. Li, and A. Strahler, "On the derivation of kernels for kernel-driven models of bidirectional reflectance," J. Geophys. Res., vol 100, pp. $21077-21090,1995$.

[45] P. Lewis and E. V. Ruiz de Lope, "Application of kernel-driven BRDF 
models and AVHRR data to monitoring land surface dynamics in the Sahel," J. Remote Sens., vol. 1, pp. 155-161, 1997.

[46] J. L. Privette., T. F. Eck, and D. W. Deering, "Estimating spectral albedo and nadir reflectance through inversion of simple bidirectional reflectance distribution models with AVHRR/moderate-resolution imaging spectrometer (MODIS) - like data," J. Geophys. Res., submitted.

[47] R. P. d'Entremont, "Meteorological applications of surface bidirectional reflectance distribution functions retrieved from satellite data," Ph.D. dissertation, Boston Univ., Boston, MA, 1997, p. 129.

[48] C. J. Tucker, C. L. Vanpraet, E. Boerwinkle, and E. Easton, "Satellite remote sensing of total dry matter accumulation in the Senegalese Sahel," Remote Sens. Environ., vol. 13, pp. 461-469, 1983.

[49] J. R. G. Townshend, C. O. Justice, D. Skole, J.-P. Malingreau, J. Cihlar, P. Teillet, F. Sadowski, and S. Ruttenberg, "The $1 \mathrm{~km}$ resolution global data set: Needs of the International Geosphere Biosphere Programme," Int. J. Remote Sensing, vol. 15, pp. 3417-3441, 1994.

[50] D. W. Deering, "Rangeland reflectance characteristics measured by aircraft and spacecraft sensors," Ph.D. dissertation, Texas A\&M Univ., College Station, 1978, p. 338.

[51] A. R. Huete, H .O. Liu, W. van Leeuwen, and K. Didan, "The use of vegetation indices in forested regions: issues of linearity and saturation," submitted for publication.

[52] H. Q. Liu and A. R. Huete, "A feedback based modification of the NDVI to minimize canopy background and atmospheric noise," IEEE Trans. Geosci. Remote Sensing, vol. 33, pp. 457-465, Mar. 1995.

[53] Y. J. Kaufman and D. Tanré, "Atmospherically resistant vegetation index (ARVI) for EOS-MODIS," IEEE Trans. Geosci. Remote Sensing, vol. 30, pp. 261-270, Jan. 1992.

[54] B. N. Holben, "Characterization of maximum value composites from temporal AVHRR data," Int. J. Remote Sensing, vol. 7, pp. 1417-1434, 1986.

[55] M. E. James and S. N. V. Kalluri, "The Pathfinder AVHRR land data set: An improved coarse resolution data set for terrestrial monitoring,' Int. J. Remote Sensing, vol. 15, pp. 3347-3363, 1994.

[56] J. Cihlar, D. Manak, and M. D'Ioro, "Evaluation of compositing algorithms for AVHRR data over land," IEEE Trans. Geosci. Remote Sensing, vol. 32, pp. 427-437, Mar. 1994

[57] W. van Leeuwen, A. R. Huete, and T. Laing, "Global vegetation index compositing approach for MODIS-EOS," J. Geophys. Res., submitted.

[58] C. L. Walthall, J. M. Norman, J. M. Welles, G. Campbell, and B. L. Blad, "Simple equation to approximate the bi-directional reflectance from vegetative canopies and bare soil surfaces," Appl. Opt., vol. 24, pp. 383-387, 1985.

[59] R. B. Myneni, R. R. Nemani, and S. W. Running, "Algorithms for estimating global land cover, LAI and FPAR from radiative transfer models," submitted for publication.

[60] R. B. Myneni, G. Asrar, and S. A. W. Gerstl, "Radiative transfer in three-dimensional leaf canopies," Trans. Theory Stat. Phys., vol. 19, pp. 205-250, 1990 .

[61] G. Asrar, R. B. Myneni, and B. J. Choudhury, "Spatial heterogeneity in vegetation canopies and remote sensing of absorbed photosynthetically active radiation: A modeling study," Remote Sens. Environ., vol. 41, pp. 85-103, 1992.

[62] R. B. Myneni, F. G. Hall, P. J. Sellers, and A. L. Marshak, "The interpretation of spectral vegetation indexes," IEEE Trans. Geosci. Remote Sensing, vol. 33, pp. 481-486, Mar. 1995.

[63] T. A. Germogenova, Local Properties of Solutions of the Transport Equation. Moscow, Russia: Nauka, 1986.

[64] S. Chandrasekhar, Radiative Transfer. New York: Dover, 1960.

[65] Y. Knyazikhin, G. Miessen, O. Panfyorov, and G. Gravenhorst, "Smallscale study of three-dimensional distribution of photosynthetically active radiation in a forest," submitted for publication.

[66] C. O. Justice, J.-P. Malingreau, and A. Setzer, "Satellite remote sensing of fires: potential and limitation," in Fire In the Environment; Its Ecological, Climatic and Atmospheric Chemical Importance, P. Crutzen and J. Goldammer, Eds. Chichester, U.K.: Wiley, 1993.

[67] R. J. Scholes, J. Kendall, and C. O. Justice, "The quantity of biomass consumed in Southern Africa,"J. Geophys. Res., vol. 101, pp. 23667-23676, 1996.

[68] L. Giglio, J. D. Kendall, and C. O. Justice, "Evaluation of global fire detection algorithms using simulated AVHRR infrared data," submitted for publication.

[69] J. D. Kendall, C. O. Justice, P. R. Dowty, C. D. Elvidge, and J G. Goldammer, "Remote sensing of fires in Southern Africa during the SAFARI 1992 campaign," in Fire in Southern Africa Savannas: Ecological and Atmospheric Perspectives, B. W. van Wilgen, M. O. Andreae, J. G. Goldammer, and J. A. Lindesay, Eds. Johannesburg, South Africa: Witwatersrand Univ. Press, 1996, pp. 89-133.
[70] C. O. Justice, J. D. Kendall, P. R. Dowty, and R. J. Scholes, "Satellite remote sensing of fires during the SAFARI campaign using NOAA advanced very high radiometer data," J. Geophys. Res., vol. 101, pp. $23851-23863,1996$.

[71] Y. J. Kaufman, C. O. Justice, L. Flynn, J. D. Kendall, L. Giglio, E. Prins, D. E. Ward, P. Menzel, and A. Setzer, "Monitoring global fires from EOS-MODIS," submitted for publication.

[72] J. M. C. Pereira, "A comparative evaluation of NOAA/AVHRR vegetation indices for burned area detection and mapping," submitted for publication.

[73] D. Roy, J. D. Kendall, J. M. C. Pereira, and C. O. Justice, "A multitemporal analysis of the use of the mid-IR in spectral vegetation indices for operational burned area mapping," Proc. RSS97: Observat. Interact., 23rd Annu. Conf. Exhib. U.K. Remote Sensing Soc., Univ. Reading, Reading, U.K., Sept. 2-4 1997, pp. 177.

[74] Y. J. Kaufman and L. A. Remer, "Detection of forests using Mid-IR reflectance: An application for aerosol studies," IEEE Trans. Geosci. Remote Sensing, vol. 32, pp. 672-683, May 1994.

[75] J. C. Roger and E. F. Vermote, "Computation and use of the reflectivity at 3.75 microns from AVHRR thermals channels," Remote Sens. Rev., vol. 15 , pp. 75-98, 1997.

[76] D. Hall, Proc. 1st MODIS Snow Ice Workshop, Greenbelt, MD, Sept. $15-17,1995$, pp. 128

[77] R. A. Pielke et al., "A comprehensive meteorological modeling system-RAMS," Meteorol. Atmos. Phys., vol. 49, pp. 69-91, 1992.

[78] T. R. Carroll, "Remote sensing of snow in the cold regions," Proc. 1st MODIS Snow Ice Workshop, Greenbelt, MD, Sept. 15-17, 1995, pp. 3-14.

[79] M. Matson, C. F. Ropelewski, and M. S. Varnadore, "An atlas of satellite-derived northern hemisphere snow cover frequency," Nat. Weath. Service, Washington, DC, 1986, p. 75.

[80] D. Hall, G. Riggs, and V. V. Salomonson, "Development of methods for mapping global snow cover using Moderate Resolution Imaging Spectroradiometer (MODIS) data," Remote Sens. Environ., vol. 54, pp. 127-140, 1995

[81] G. A. Riggs, D. K. Hall, and S. Ackerman, "Sea ice detection with the MODIS airborne simulator (MAS) instrument," Remote Sens. Environ., to be published.

[82] W. Rosenthal and J. Dozier, "Automated mapping of montane snow cover at subpixel resolution from the Landsat Thematic Mapper," Water Resour. Res., vol. 32, pp. 115-130, 1996.

[83] A. Strahler, J. R. G. Townshend, D. Muchoney, J. Borak, M. Friedl, S. Gopal, A. Hyman, A. Moody, and E. Lambin, 1996, MODIS Land Cover Product Algorithm Theoretical Basis Document (ATBD) Version 4.1, NASA EOS-MTPE Documentation, 1996, p. 102.

[84] M. A. Friedl, C. E. Brodley, and A. Strahler, "Maximizing land cover classification accuracies produced by decision trees at continental to global scales," submitted for publication.

[85] S. Gopal, C. Woodcock, and A. Strahler, "Fuzzy ARTMAP classification of global land cover from the 1 degree AVHRR data set," submitted for publication.

[86] J. R. Key, J. B. Collins, C. Fowler, and R. S. Stone, "High-latitude surface temperature estimates from thermal satellite data," Remote Sens. Environ., vol. 61, pp. 302-309, 1997.

[87] R. DeFries, M. Hansen, and J. R. G. Townshend, "Proportional estimation of land cover characteristics from satellite data," Proc. 1996 Int. Geosci. Remote Sensing Symp., Lincoln, NE, vol. 1, May 27-31, 1996, pp. $535-537$

[88] E. F. Lambin and A. H. Strahler, "Change-vector analysis: A tool to detect and categorize land-cover change processes using high temporalresolution satellite data," Remote Sens. Environ., vol. 48, pp. 231-244, 1994.

[89] , "Indicators of land-cover change for change-vector analysis in multitemporal space at coarse spatial scales," Int. J. Remote Sensing, vol. 15, pp. 2099-2119, 1994

[90] E. F. Lambin and D. Erlich, "Land-cover changes in sub-Saharan Africa (1982-1991): Application of a change index based on remotely sensed surface temperature and vegetation indices at a continental scale," Remote Sens. Environ., vol. 61, pp. 181-200, 1997.

[91] J. L. Monteith, "Climate and the efficiency of crop production in Britain," Philos. Trans. R. Soc. Lond., vol. 281, pp. 277-294, 1977.

[92] S. W. Running, R. R. Nemani, and J. M. Glassy, "Global net photosynthesis and terrestrial net primary productivity from the Earth observing system," Methods Ecosyst. Sci., to be published.

[93] R. R. Nemani and S. W. Running, "Landcover characterization using multi-temporal red, near-IR and thermal IR data from NOAA AVHRR," Ecol. Applicat., vol. 7, no. 1, pp. 79-90, 1997.

[94] D. Baldocchi, R. Valentini, S. W. Running, W. Oechel, and R. Dahlman. 
"Strategies for measuring and modeling carbon dioxide and water vapor fluxes over terrestrial ecosystems," Global Change Biol., vol. 2, pp. 159-168, 1996.

[95] MTPE EOS Reference Handbook, G. Asrar and R. Greenstone, Eds., NASA EOS Project Science Office, Goddard Space Flight Center, Greenbelt, MD, vol. 215, 1995, p. 27.

[96] C. O. Justice, G. B. Bailey, M. E. Maiden, S. I. Rasool, D. E. Strebel, and J. D. Tarpley, "Recent data and information system initiatives for remotely sensed measurements of the land surface," Remote Sens. Environ., vol. 51, pp. 235-244, 1995.

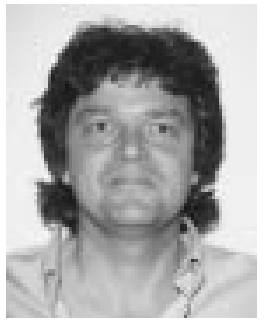

Christopher O. Justice received the Ph.D. degree in geography from the University of Reading, Reading, U.K. in 1977.

He became an NRC Post Doctoral Research Fellow at NASA's Goddard Space Flight Center (GSFC), Greenbelt, MD, in 1978. He then spent two years with the European Space Agency (ESA) at the Earthnet Programme Office, Frascati, Italy. In 1983, he returned to the United States and joined the University of Maryland, College Park. He was a Senior Research Scientist in the Geography Department working as part of with the Global Inventory Monitoring and Modeling Studies (GIMMS) Group at NASA/GSFC. He is currently a Research Professor in the Department of Environmental Sciences, University of Virginia, Charlottesville. He is the MODIS land discipline leader.

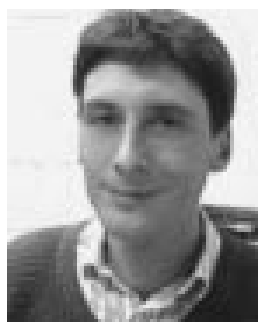

Eric Vermote (M'95) received an engineering degree in computer science from Ecoles des Hautes Etudes Industrielles (H.E.I.), Lille, France, in 1986, and the Ph.D. degree in atmospheric optics from the University of Lille in 1990.

$\mathrm{He}$ is currently an Associate Research Scientist in the Department of Geography, University of Maryland, College Park, working at NASA's Goddard Space Flight Center, Greenbelt, MD. He is an EOS/MODIS Science Team Member responsible for the atmospheric correction over land surfaces in the visible-to-middle infrared. His research interests cover radiative transfer modeling, vicarious calibration, atmospheric correction, and aerosol retrieval.

John R. G. Townshend received the B.Sc. degree in 1967 and the $\mathrm{Ph} . \mathrm{D}$. degree in 1971 from the University College London, London, U.K.

$\mathrm{He}$ is a Professor at the University of Maryland (UM), College Park, where he holds joint appointments in the Department of Geography and the Institute for Advanced Computing Studies. He is also currently Acting Director of the Earth System Science Interdisciplinary Center, UM, and chairs the Joint Scientific and Technical Committee of the Global Climate Observing System. He has been a member of the MODIS Science Team since 1996.

Ruth Defries received the Ph.D. degree in physical geography from The Johns Hopkins University, Baltimore, MD.

She is currently an Associate Research Scholar in the Department of Geography, University of Maryland, College Park. Previous positions were held at the National Academy of Sciences and the Indian Institute of Technology, Bombay. She has edited and authored several books on the subject of global environmental change and papers on remote sensing of global vegetation.

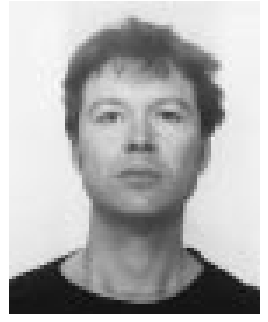

David P. Roy received the B.Sc. degree in geophysics from the University of Lancaster, Lancaster, U.K., in 1987, the M.Sc. degree in remote sensing and image processing from the University of Edinburgh Edinburgh, Scotland, in 1988, and the $\mathrm{Ph} . \mathrm{D}$. degree on the geometric correction of airborne scanner imagery from the University of Cambridge, Cambridge, U.K., in 1993.

He held research fellowships at the United Kingdom National Environment Research Council for Thematic Information Systems from 1993 to 1994 and at the Space Applications Institute of the Joint Research Center of the European Commission, Italy, from 1994 to 1996 . He is currently an Assistant Research Scientist in the Department of Geography, University of Maryland, College Park, working at NASA's Goddard Space Flight Center, Greenbelt, MD. His research interests include small-scale forest mapping, the quality assurance of the EOS/MODIS land products, and development of a MODIS postlaunch burn scar product.

Dorothy K. Hall, photograph and biography not available at the time of publication.

this issue, p. 1041

Jeffrey L. Privette (M'96) received the Ph.D. degree in aerospace engineering sciences from the University of Colorado, Boulder, in 1994.

$\mathrm{He}$ has been involved with remote sensing of land biophysical parameters since 1989. He is currently a Physical Scientist with NASA's Goddard Space Flight Center, Greenbelt, MD, and is primarily involved with the validation of EOS-AM1 products over global test sites.

George Riggs, photograph and biography not available at the time of publication.

Alan Strahler (M'86) received the B.A. and Ph.D. degrees in geography from The Johns Hopkins University, Baltimore, MD, in 1964 and 1969, respectively.

He was with Hunter College, City University of New York, the University of California, Santa Barbara, and the University of Virginia, Charlottesville $\mathrm{He}$ is currently Professor of Geography and Researcher in the Center for Remote Sensing, Boston University, Boston, MA. Originally trained as a biogeographer, he has been actively involved in remote-sensing research since 1978. He has been a Principal Investigator on numerous NASA contracts and grants, and he is currently a member of the Science Team for the EOS MODIS instrument. His primary research interests are directed toward modeling the bidirectional reflectance distribution function (BRDF) of discontinuous vegetation covers and retrieving physical parameters describing ground scenes through inversion of BRDF models using directional radiance measurements. He is also interested in the problem of land cover classification using multitemporal, multispectral, multidirectional, and spatial information, as acquired in reflective and emissive imagery of the earth's surface.

Dr. Strahler was awarded the AAG/RSSG Medal for Outstanding Contributions to Remote Sensing in 1993.

Wolfgang Lucht, photograph and biography not available at the time of publication. 
Ranga B. Myneni, for a photograph and biography, see this issue, p. 1087.

Yuri Knyazikhin received the M.S. degree in applied mathematics from Tartu University, Estonia, and the Ph.D. degree in numerical analysis from the N.I Muskhelishvilli Institute of Computing Mathematics, the Georgian Academy of Sciences, Tbilisi, Georgia, in 1978 and 1985, respectively.

He was a Research Scientist at the Institute of Astrophysics and Atmospheric Physics and Tartu University, Computer Center of the Siberian Branch of the Russian Academy of Sciences, from 1978 to 1990 . He was an Alexander von Humboldt Fellow from 1992 to 1993, and he worked at the University of Goettingen, Goettingen, Germany, from 1990 to $1996 . \mathrm{He}$ is currently a Research Associate Professor in the Department of Geography, Boston University, Boston, MA. He has worked and published in areas of numerical, integral, and differential equations, theory of radiation transfer in atmospheres and plant canopies, remote sensing of the atmosphere and plant canopies, ground-based radiation measurements, forest ecosystem dynamics, and modeling sustainable multifunctional forest management.

Steve W. Running, photograph and biography not available at the time of publication.

Rama R. Nemani, photograph and biography not available at the time of publication.

Zhenming Wan (S'81-M'84), for a photograph and biography, see p. 225 of the January 1998 issue of this TransaCTIONS.

Alfredo R. Huete, photograph and biography not available at the time of publication.

Wim van Leeuwen received the M.Sc. degree in soil science and soil fertility from the Agricultural University of Wageningen, The Netherlands, in 1988 and the Ph.D. degree in soil and water science from the University of Arizona, Tucson, in 1995 .

His research interest include the retrieval of soil and vegetation biophysical parameters from remotely sensed data on a regional and global scale, remote sensing applications, and monitoring of global change. He directed and worked on numerous remote-sensing field and validation experiments and since 1995 has been a Research Scientist in the Terrestrial Biophysics and Remote Sensing Laboratory, Department of Soil, Water, and Environmental Science, University of Arizona. Since 1996, he has been an Associate Team Member of the Land discipline group for the Moderate Resolution Imaging Spectroradiometer on NASA's Earth Observing System (MODIS/EOS).

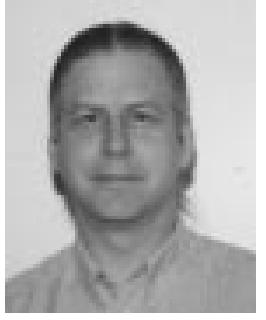

Robert E. Wolfe received the B.Sc. degree in mathematics and physics from Bridgewater College, Bridgewater, VA, in 1980 .

He is currently a Chief Scientist with Raytheon STX working at NASA's Goddard Space Fligh Center, Greenbelt, MD. He is working with the MODIS Science Team and coordinates MODIS geolocation and Level 3 land product generation. Before joining MODIS, he spent over ten years building processing systems for high-resolution imagery sensed by the Landsat TM and SPOT sensors. His research interests include satellite image geolocation, elevation model generation, and the production of terrestrial geophysical parameters from satellite data.

Louis Giglio is currently pursuing the M.S. degree in applied physics at The Johns Hopkins University, Baltimore, MD.

$\mathrm{He}$ is a member of the the Biospheric Sciences branch, NASA's Goddard Space Flight Center, Greenbelt, MD, where he studies satellite monitoring of biomass burning on a global scale.

Jan-Peter Muller, for a photograph and biography, see this issue, p. 1087.

Philip Lewis, photograph and biography not available at the time of publication.

Michael J. Barnsley, photograph and biography not available at the time of publication. 